\title{
Impairments of Lexical-Semantic Processing in Aphasia: Evidence from the Processing of Lexical Ambiguities
}

\section{Peter Hagoort}

\author{
Max Planck Instituse for Psycholinguistics, Nijmegen. The Nesherlands
}

Broca's and Wernicke's aphasics performed speeded lexical decisions on the third member of auditorily presented triplets consisting of two word primes followed by either a word or a nonword. In three of the four priming conditions. the second prime was a homonym with two unrelated meanings. The relation of the first prime and the target with the two meanings of the homonym was manipulated in the different priming conditions. The two readings of the ambiguous words either shared their grammatical form class (noun-noun ambiguities) or not (noun-verb ambiguities). The silent intervals between the members of the triplets were varied between 100, 500, and $1250 \mathrm{msec}$. Priming at the shortest interval is mainly attributed to automatic lexical processing. and priming at the longest interval is mainly due to forms of controlled lexical processing. For both Broca's and Wernicke's aphasics overall priming effects were obtained at ISIs of 100 and 500 msec, but not at an $1 \mathrm{Sl}$ of $1250 \mathrm{msec}$. This pattern of results is consistent with the view that both types of aphasics can automatically access the semantic lexicon, but might be impaired in integrating lexical-semantic information into the context. Broca's aphasics showed a specific impairment in selecting the contextually appropriate reading of noun-verb ambiguities. which is suggested to result from a failure either in the on-line morphological parsing of complex word forms into a stem and an inflection or in the on-line exploitation of the syntactic implications of the inflectional suffix. In a final experiment patients were asked to explicitly judge the semantic relations between a subset of the primes that were used in the lexical decision study. Wernicke's aphasics performed worse than both Broca's aphasics and normal controls, indicating a specific impairment for these patients in consciously operating on automatically accessed lexical-semantic information. 1993 Academic Press, inc.

This research was supported by a stipend from the Max-Planck-Gesellschaft zur Förderung der Wissenschaften. I thank Colin Brown. Pienie Zwitserlood, and two anonymous reviewers for their helpful comments on an earlier version of this article. Address reprint requests to Peter Hagoort, Max Planck Institute for Psycholinguistics. Wundtlaan 1, NL6525 XD Nijmegen, The Netherlands. 


\section{INTRODUCTION}

Accessing the mental lexicon and activating the information specified by its lexical entries are central processes in both language production and language comprehension (Frauenfelder \& Tyler, 1987; Levelt, 1989). Lexical information is normally made available very rapidly, due in part presumably to the highly efficient internal organization of the mental lexicon. It is assumed that the lexicon is organized as a network of representational nodes that either increase or decrease their levels of activation via excitatory or inhibitory links with other nodes (e.g., McClelland \& Rumelhart, 1981). At the lexical-semantic level of representation, the network is thought to be organized according to the degree of semantic similarity between the nodes. Nodes representing semantically related words are assumed to be more strongly connected (i.e., via direct links) than nodes for unrelated words (Collins \& Loftus, 1975).

In many aphasic patients lexical-semantic processing is severely disrupted. A number of studies (e.g., Goodglass \& Baker, 1976; Whitehouse, Caramazza, \& Zurif, 1978; Zurif, Caramazza, Myerson, \& Galvin, 1974) have shown that especially Wernicke's aphasics show a deficit in activating the semantic information associated with lexical items. Zurif et al. (1974) presented aphasic and control subjects with triplets of words and required them to select the two that went best together. The words varied along semantic dimensions such as human-nonhuman, ferociousharmless, etc. In contrast to the normal control subjects and the Broca's aphasics, the Wernicke patients were unable to group the words according to their shared semantic features. The studies by Goodglass and Baker (1976) and by Whitehouse et al. (1978) also required subjects to make explicit semantic judgements. These studies confirmed the findings of Zurif et al. in that for Wernicke's aphasics clear deficits in lexicalsemantic processing were inferted from the results. The underlying deficit was thought to be a (partial) loss of the semantic information in the lexical entries or a disruption of the internal organization of the mental lexicon. Broca's aphasics, however, were claimed to have a more or less intact semantic lexicon (Zurif et al., 1974).

A number of recent studies (Blumstein, Milberg, \& Shrier, 1982; Chenery, Ingram, \& Murdoch, 1990; Katz, 1988; Milberg \& Blumstein, 1981; Milberg, Blumstein, \& Dworetzky, 1987) cast serious doubts on this account of lexical-semantic deficits. These studies used a word priming paradigm with a lexical decision task. In this task subjects are required to decide whether a sequence of letters or sounds is a word or not. Decision times on word targets can be speeded up by a preceding word with an associative/semantic relation to the target word (Meyer \& Schvaneveldt, 1971). Aphasic patients and control subjects were presented with prime-target pairs, or triplets (Milberg et al., 1987), consisting of words that were either associatively related or unrelated. Despite significantly 
longer response latencies, Wernicke's aphasics consistently showed the same pattern of results as the normal control subjects; that is, both the control subjects and the Wernicke patients needed less time to recognize the target as a word when it was preceded by an associatively related word. Surprisingly enough, the Broca's aphasics had a much less stable pattern of performance. In some studies they showed the expected priming effect (Blumstein, Milberg, \& Shrier, 1982; Katz, 1988; Milberg, Blumstein, \& Dworetzky, 1988), whereas in other studies this priming effect was absent (Milberg \& Blumstein, 1981; Milberg, Blumstein, \& Dworetzky, 1987).

At least two conclusions can be drawn from these results. First, for many aphasic patients lexical-semantic deficits are not due to a loss of "the integrity of the stored lexical knowledge base" (Milberg et al., 1987, p. 139), but rather relate to a problem in the processing operations on lexical-semantic information.

Second, the way in which lexical-semantic information is used in tasks requiring explicit semantic judgements might be different from the access of lexical-semantic information under implicit task conditions, which do not focus the subjects on the semantics of the presented words.' This difference between both types of tasks has been related (e.g., Milberg \& Blumstein, 1981; Milberg et al., 1987) to the general dichotomy between automatic and controlled processing (Posner \& Snyder, 1975; Shiffrin \& Schneider, 1977). Automatic processes are fast, of short duration, and do not require attention or awareness. Controlled processing is slower, involves resource capacity, and is under the subject's intentional control, thereby allowing the subject's expectancies and strategies to play a role.

On the basis of the consistently reported semantic facilitation in lexical decision tasks, Milberg et al. (1987) claim that Wernicke's aphasics are able to automatically access word meanings, but are impaired in explicitly "analyzing" the meaning of words. The latter skill presupposes that the lexical information can be processed in a more controlled way. With some caution, the authors suggest the opposite pattern for Broca's aphasics. These patients are claimed to have little or no difficulty in controlled processing, but they do show an impairment in automatic access to lexical-semantic information. The claim for loss of automaticity in Broca's aphasia has also been made for other leveis of language processing. Blumstein (1982) suggested that agrammatic comprehension might be

\footnotetext{
' A possible argument against this account of the diverging pattern of results in studies using different tasks is to argue that priming studies using associatively related words do not tap into the "real" lexical semantics. However, this argument will not get us very far, for two reasons. First, there is evidence that the mechanisms underlying associative and semantic priming are the same (De Groot, 1990). Second, fluent aphasics are also shown to be sensitive to purely semantic (nonassociative) priming (Friedman, Glosser, \& Diarnond, 1988).
} 
caused by a loss of automaticity in accessing linguistic information at all levels of representation. Others have suggested a loss of the ability to automatically access a subset of lexical items, i.e., closed class words (e.g., Bradley, Garrett, \& Zurif, 1980; Friederici, 1988b), or to automatically process syntactic information (Friederici \& Kilborn, 1989).

\section{Priming as an Index of Automatic and Controlled Processing}

The claim for a dissociation between automatic and controlled lexicalsemantic processing in both Broca's and Wernicke's aphasia is based upon a comparison of the results in two completely different tasks. The results in a lexical decision task are compared with the results in a set of tasks requiring the subject to make explicit semantic decisions. It is thereby assumed that the lexical decision task taps into the process of automatic access to lexical-semantic information. However, this assumption requires further qualification. There is convincing evidence (Balota \& Chumbley, 1984: De Groot, 1984; De Groot, Thomassen, \& Hudson. 1986; Keefe \& Neely, 1990; Neely, 1977, 1991; Neely, Keefe, \& Ross, 1989; Seidenberg, Waters, Sanders, \& Langer, 1984) that priming effects can be attributed to a number of different mechanisms. Neely and Keefe (1989) argue that three different processes have to be assumed to account for the results in a large number of priming studies in which a lexical decision task has been used. Only one of these processes is claimed to be automatic; the remaining two are forms of controlled processing.

The first process is automatic spread of activation (ASA). Based on the assumption that a strong (or direct) link exists between semantically/ associatively related nodes in the lexical-semantic network, activation of a node that arises in response to the presentation of the corresponding word spreads along the paths in the network to nodes representing words that are related in meaning. As a consequence, the activated nodes representing related word targets need less time for subsequent processing in a lexical decision or a naming task. However, the processing of unrelated words will be unaffected, since the activation levels of their nodes in the network will not have changed. Therefore, ASA is assumed to only facilitate the processing of related targets and not to inhibit the processing of unrelated target words (Neely, 1977; Posner \& Snyder, 1975). ASA is especially effective when the stimulus-onset-asynchrony (SOA) between prime and target is short. Thus ASA contributes to priming effects only within a restricted temporal window. In priming studies using a visual presentation of primes and targets this temporal window ranges around an SOA of some $500 \mathrm{msec}$ (De Groot, 1984; Neely, 1977; Prather \& Swinney, 1988). After this short temporal window, automatic priming rapidiy decreases.

A second mechanism that contributes to semantic priming effects is 
expectancy. Subjects can generate an expectancy set on the basis of the information contained by the prime. This expectancy set consists of words that are potential targets. If the target is a member of this set, it will be recognized more quickly. If it is not, recognition will be slowed down. Unlike ASA, expectancy-induced priming therefore not only facilitates the processing of expected targets, but also inhibits the processing of unexpected targets (Neely, 1977). Posner and Snyder (1975) propose that this second priming mechanism is a form of controlled processing. As such expectancy-induced priming effects can be influenced by instruction and by the list structure of the materials (e.g., the proportion of related prime-target pairs). These factors can modulate the probability that subjects will generate an expectancy set of words related to the prime (Keefe \& Neely, 1990). In contrast to ASA, expectancy is a rather slow process because it takes time to generate the expectancy set from the prime. This implies that expectancy-induced priming is only effective at longer SOAs between primes and targets.

The third mechanism in Neely and Keefe's (1989) hybrid three-process theory is semantic matching. In a lexical decision task subjects are assumed to match primes and targets for semantic similarity and bias their decisions according to the results of this matching process. The detection of a relation between primes and targets leads to a bias for the "yes" response. If no relation is detected, the "no" response will be biased. Semantic matching results in facilitation for related target words. For unrelated target words, however, the semantic matching is without success, inducing a bias to respond with "no". As a consequence, the required "yes" response for these target words will be inhibited. In contrast to expectancy semantic matching can also be effective with relatively short SOAs between primes and targets (De Groot, 1984; but see Neely, 1991).

In sum, three different processes have been proposed to account for the results in priming studies using a lexical decision task. Of these processes, only automatic spread of activation is an automatic consequence of access to the prime's semantic node. Expectancy is a much slower, controlled process that gets triggered upon accessing the prime and can be influenced by instruction and by the list structure of the materials. ASA and expectancy both yield priming by speeding up the access to the lexical-semantic node that represents the target. In contrast to these two processes, semantic matching is a postlexical process which operates only after target presentation.

A powerful way to manipulate the relative contributions of automatic and controlled lexical processing to the overall priming effect is by varying the interval between primes and targets. However, to date all priming studies with aphasic patients have used a fixed interval between primes and targets. The study by Milberg and Blumstein (1981) presented the 
stimuli visually with an SOA of 2000 msec between primes and targets. All the studies with an auditory stimulus presentation used a silent interval (ISI) of $500 \mathrm{msec}$ between primes and targets (Blumstein et al., 1982; Chenery et al., 1990; Katz, 1988; Milberg et al., 1987, 1988). For the following two reasons the ISI in the auditory modality cannot be directly compared to delays between primes and targets in the visual modality. First, for the majority of polysyllabic words the recognition point for their spoken word forms precedes the end of the word (Marslen-Wilson, 1984, 1987). Second, semantic priming effects for spoken words have been obtained $150 \mathrm{msec}$ after word onset, which is well before the end of the word (Zwitserlood, 1989). This implies that the ISI of $500 \mathrm{msec}$ underestimates the effective interval between primes and targets. Given the relatively long delays between primes and targets in all these priming studies with aphasic patients, one cannot safely conclude that they only or most strongly tapped automatic instead of controlled lexical-semantic processing. The dissociation between the priming results of Broca's and Wernicke's aphasics and their results in studies testing lexical-semantic processing with completely different tasks might also be explained in terms of task-specific factors. In conclusion, it is far from clear whether these different patterns of results obtained with completely different tasks can be explained in terms of impairments in either one of two separate lexical processing routines.

The present priming study with aphasic patients differs from all its predecessors in that three different intervals between primes and targets are used: a short, a medium, and a long one. This ISI manipulation serves the purpose of separating automatic and controlled lexical-semantic processing under exactly the same task conditions. In this way, a possibly differential pattern of results for short and long ISIs can no longer be attributed to differences in task aspects. Comparing the priming results obtained for aphasic patients at these three different ISIs, therefore, is a more straightforward test of the claims that Broca's and Wernicke's aphasics differ with respect to lexical-semantic processing in that the former are impaired in automatic and the latter in controlled processing of lexical-semantic information. In this way the results allow firmer conclusions with respect to possible impairments in the underlying processing mechanisms.

\section{Introduction to the Experiments}

The priming study showing the most marked difference between Broca's and Wernicke's aphasics is the one by Milberg et al. (1987). In this study, subjects were presented with two primes followed by a target. In three of the four priming conditions, the second prime was a homonym with two unrelated meanings. The relation of the first prime and the target 
with the two independent meanings of the homonym was manipulated in the different priming conditions. In the concordant priming condition, the first and the third word were related to the same reading of the ambiguous second word (e.g., SHORE-BANK-RIVER). In the discordant priming condition the first and third word were related to different meanings of the ambiguous word (e.g., MONEY-BANK-RIVER). The neutral condition started with a word that was unrelated to either reading of the ambiguous word, and, moreover, unrelated to the last word of the triplet (e.g., $T E N T-B A R K-T R E E$ ). Finally, the unrelated condition consisted of three unrelated, unambiguous words (e.g., DOG-TENT-TREE). The most remarkable result of the Milberg et al. (1987) study was the significant interaction between the patient groups and the priming conditions. The Wernicke's aphasics showed the same priming effects as the normal control subjects, despite their significantly longer overall response times. The Broca's aphasics, however, did not show a significant priming effect. Milberg et al. suggest that processing deficits in Broca's aphasia (and in other patients with frontal lobe lesions) might be due to a general deficit in automatically processing stimulus contiguities. "As a result, they may fail to be influenced by the nature of the relation between contiguous elements. Presumably, the greater the number of elements to be related (in this case word triplets compared to word pairs), the more likely a deficit will emerge" (Milberg et al., 1987; pp. 147-148). This, then, should explain why Broca patients did show a priming effect in most studies using prime-target pairs (Blumstein et al., 1982; Katz, 1988; Milberg et al., 1988), whereas no priming effects were obtained when subjects were required to process three instead of two words.

In testing lexical-semantic processing deficits in aphasia, I therefore decided to extend and modify the Milberg et al. (1987) study in which the difference between Wernicke's and Broca's aphasics was found to be most marked.

As in the experiment by Milberg et al., in this study the processing of ambiguous words in aphasic patients is tested as a means to investigate the possible deficits of Broca's and Wernicke's aphasics in lexicalsemantic processing.

The results of a number of studies addressing the role of word contexts in the resolution of lexical ambiguity are equivocal. In some studies selective activation of the biased meaning of ambiguous words has been reported for normal subjects (Balota \& Duchek, 1991; Schvaneveldt, Meyer, \& Becker, 1976). Other studies, however, report activation for both meanings of the ambiguous words (Marcel, 1980; Oden \& Spira, 1983). The overall picture for the processing of ambiguous words in a word context seems to suggest that all meanings are initially accessed, with their levels of activation modulated by the context (Simpson, 1984).

In so far as the obtained priming effects in this type of context are due 
to the automatic spread of activation, the biased meaning of an ambiguous word increases its level of activation by receiving some of the activation from the prime's semantic node, resulting in a reduction of the latency to access this meaning of the ambiguous word upon encountering the associated word form. The latency to access the unbiased meaning, however, should be the same regardless of whether another meaning of the ambiguous word is primed. The automatic spread of activation leaves the nonbiased meaning unaffected (but see for a slightly different proposal Cottrell \& Small, 1983). Targets related to the biased as well as those related to the unbiased meaning will, therefore, show facilitation relative to an unrelated target.

A different pattern should emerge when priming is not only induced by automatic spread of activation. For instance, the suppression of the unbiased meaning is often assumed to be the result of some form of controlled processing. One proposal is that after the initial automatic access to all meanings of an ambiguous word, attention is allocated to the contextually appropriate one, with the inhibition of the inappropriate meaning(s) as the concomitant result (cf. Simpson, 1984).

In the remainder I will use selective activation as a shorthand for rapid contextual selection of the appropriate meaning. It leaves open the possibility that initially all meanings are accessed following which the word context rapidly selects the appropriate one.

In contrast to other priming studies with aphasic patients, the present study varies the ISI between the auditorily presented primes and targets. Three ISls are used in separate experiments: 100,500 , and $1250 \mathrm{msec}$. The shortest ISI is expected to be within the temporal window of automatic lexical-semantic processing. The longest ISI is supposed to mainly tap more controlled lexical-semantic processing.

In addition to the variations in ISI, the type of ambiguity is explicitly manipulated. The stimuli consist of both noun-noun and noun-verb ambiguities. It has been suggested that the two types of ambiguity have a different lexical status, showing up as a difference in the pattern of results in studies on the resolution of lexical ambiguity (Seidenberg, Tanenhaus, Leiman, \& Bienkowski, 1982). The representational difference between the two types of ambiguity is due to the fact that the two independent meanings of noun-verb ambiguities are associated with different grammatical form classes, while those of the noun-noun ambiguities share their form class representation. It is possible that especially Broca's aphasics show a deviant pattern of performance for these noun-verb ambiguities, which might be due to an impairment in the on-line exploitation of syntactic information associated with the different grammatical form classes (e.g., as encoded in inflectional affixes).

A final experiment manipulates the task aspects. In addition to the lexical decision task, subjects are given a task in which they are requested 
to judge the semantic relation between a subset of the words used in the priming experiments. In this way, the contribution of task aspects to the outcome of studies on lexical-semantic processing can be established with the same group of aphasic patients.

\section{EXPERIMENT 1}

Experiment 1 was a replication of the Milberg et al. (1987) study with respect to its design and its $1 S 1$ between the two prime words and the target. It differed, however, in three aspects from the experiment by Milberg et al. First, the materials were in Dutch. Second, the type of ambiguity was introduced as a separate factor. Third, repetition effects were explicitly controlled for (for a discussion of this point, see Hagoort, 1989).

\section{Method}

Subjects. The subjects in this experiment were 18 aphasic patients and 12 elderly subjects from the subject pool of the Max Planck Institute for Psycholinguistics. All subjects were right-handed. The elderly subjects were paid for their participation and served as the normal control group. The normal controls were approximately matched with the aphasic patients in age and education. All aphasic patients were administered the Dutch version of the Aachen Aphasia Test (AAT) (De Bleser. Wilimes, Graetz. \& Hagoort. 1991: Graetz, De Bleser, Willmes, \& Heeschen, 1991). Patients were diagnosed by aphasia (ype both on the basis of their AAT results and on the basis of a transcribed sample of their spontaneous speech. The characteristics of the sponaneous speech were judged by three staff members of the Aphasia Project at the Max Planck Institute. Twelve patients were unanimously diagnosed as Broca's aphasics, and five received the unanimous diagnosis of Wernicke's aphasia. One patient was diagnosed as anomic. All aphasic subjects had a cerebral vasculat accident (CVA) in the left hemisphere. Except for one Wernicke patient who was tested 4 months postonset, all patients had an aphasia for at least 1 year when testing began. Table I shows a summary of the patients age, gender. scores on the Token Test, performance on the AAT subtest on comprehension, and CT scan localization of lesion.

The mean age for the normal control subjects was 57.5 years (range 5I-65). the mean age for the Broca patients was $\mathbf{5 4 . 1}$ years, and the mean age for the Wernicke patients was 67.6 years.

Materials. The stimuli consisted of auditorily presented triplets of sound sequences, the first two of which were real Dutch words serving as the primes. The third one served as the target. The target could be either a word or a nonword. In three of the four priming conditions for real word targets, the second prime was a homograptic homophone with two or more unrelated meanings. These ambiguous primes were taken from an extensively pretested list of Dutch words with two or more independent meanings. Sixteen noun-noun ambiguities, 15 noun-verb ambiguities, and I adjective-verb ambiguity were selected, all with a relatively strong associate for both meanings.

As in the Milberg et al. (1987) study, there were four priming conditions for the word targets. Table 2 gives examples of the materials in the four priming conditions and in the two ambiguity types.

In the concordant condition, the first prime and the target were related to the same meaning of the second (ambiguous) prime. In the discordant condition, the first prime and the target word were related to alternative meanings of the second prime. In the neutral 
TABLE 1

Individual Patient History and Results on Subtests of the AAT

\begin{tabular}{|c|c|c|c|c|c|}
\hline Diagnosis & Age & Sex & $\begin{array}{l}\text { Token } \\
\text { test }\end{array}$ & $\begin{array}{l}\text { Comprehension } \\
\text { score AAT }\end{array}$ & Lesion site \\
\hline Broca's & 58 & $\mathbf{M}$ & 2 & $104 / 120$ & $\begin{array}{l}\text { Left middle cerebral artery } \\
\text { distribution }\end{array}$ \\
\hline Broca's & 62 & M & 24 & $76 / 120$ & $m$ \\
\hline Broca's & 54 & $\mathbf{F}$ & 30 & $93 / 120$ & $\begin{array}{l}\text { Left insula with extension } \\
\text { into lefe parietal region }\end{array}$ \\
\hline Broca's & 54 & $\mathbf{M}$ & 37 & $73 / 120$ & $\begin{array}{l}\text { Left middle cerebral artery } \\
\text { distribution }\end{array}$ \\
\hline Broca's & 59 & $\mathrm{~F}$ & 9 & $98 / 120$ & Left frontotemporal \\
\hline Broca's & 60 & $\mathbf{M}$ & 21 & $102 / 120$ & $\begin{array}{l}\text { Left insula and middle tem- } \\
\text { poral gyruss }\end{array}$ \\
\hline Broca's & 23 & $\mathbf{M}$ & 34 & $100 / 120$ & $\begin{array}{l}\text { Left frontal with parietal } \\
\text { involvement }\end{array}$ \\
\hline Broca's(*) & 33 & $\mathbf{F}$ & 31 & $85 / 120$ & $\begin{array}{l}\text { Left frontotemporal with } \\
\text { subcortical extension } \\
\text { into temporoparietal } \\
\text { region }\end{array}$ \\
\hline Broca's(*) & 74 & $\mathbf{M}$ & 11 & $97 / 120$ & $\begin{array}{l}\text { Left insula; involvement of } \\
\text { temporal lobe: superior } \\
\text { and medial temporal gyri }\end{array}$ \\
\hline Broca ${ }^{*}\left(^{*}\right)$ & 48 & $\mathbf{M}$ & 42 & $86 / 120$ & $\begin{array}{l}\text { Left middle cerebral artery } \\
\text { distribution }\end{array}$ \\
\hline Broca's(*) & 56 & $\mathbf{M}$ & 33 & $99 / 120$ & Left temporoparietal \\
\hline Broca's(*) & 68 & $\mathbf{F}$ & 20 & $90 / 120$ & $\begin{array}{l}\text { Left subcortical lesion: } \\
\text { Extension from the basal } \\
\text { ganglia up to paraventric- } \\
\text { ular white matter }\end{array}$ \\
\hline Wernicke's & 72 & $\mathbf{M}$ & 24 & $59 / 120$ & $\begin{array}{l}\text { Left occipitolemporal in- } \\
\text { farction with involve- } \\
\text { ment of Wernicke's area }\end{array}$ \\
\hline Wernicke's & 76 & $\mathbf{M}$ & 32 & $83 / 120$ & $\begin{array}{l}\text { Posterior distribution of the } \\
\text { left middle cerebral ar- } \\
\text { tery; left parietal: exten- } \\
\text { sions into temporal and } \\
\text { occipital lobes }\end{array}$ \\
\hline Wernicke's & 70 & $\mathbf{M}$ & 43 & $77 / 120$ & $\begin{array}{l}\text { Middle and anterior two- } \\
\text { third of left temporal } \\
\text { lobe }\end{array}$ \\
\hline Wernicke's & 64 & M & 19 & $82 / 120$ & $\begin{array}{l}\text { Left posterior superior tem- } \\
\text { poral lobe with parietal } \\
\text { involvement: Wernicke's } \\
\text { area }\end{array}$ \\
\hline Wernicke's( $\left.{ }^{*}\right)$ & 56 & $\mathbf{M}$ & 42 & $90 / 120$ & $\begin{array}{l}\text { Left superior temporal gy- } \\
\text { ns including Wemicke's } \\
\text { area; extensions superi- } \\
\text { orly and anteriorly into } \\
\text { parietal and frontal lobes }\end{array}$ \\
\hline Anomic (*) & 52 & $\mathbf{M}$ & 39 & $82 / 120$ & - \\
\hline
\end{tabular}

Note. The patients marked with an asterisk only participated in Experiment I. All other patients also participated in Experiments 2, 3, and 4. Scores on the Token Test are corrected for age. Severity of the disorder as indicated by the Token Test: no disorder (0-3); light (4-10); middle (11-33); severe (>33). Severity of the comprehension disorder as indicated by the AAT subtest Comprehension (includes word and sentence comprehension in auditory and visual modalities): severe (0-59); middle (60-89); light (90-104); no disorder (105-120). Ranges of severity are based on the norms for the German version of the AAT. 
TABLE 2

Examples of the Prime and Target Words in Each Condition

Priming

condition Prime I Prime 2 Target word

Type of Ambiguity: Noun-Noun

$\begin{array}{lllll}\text { Concordant } & \text { bier } & \text { kater } & \text { DRANK } & \text { (beer-tomcat/hangover-DRINK) } \\ \text { Discordant } & \text { poes } & \text { kater } & \text { DRANK } & \text { (cat-tomcat/hangover-DRINK) } \\ \text { Neutral } & \text { piano } & \text { kater } & \text { DRANK } & \text { (piano-tomcat/hangover-DRINK) } \\ \text { Unrelated } & \text { poes } & \text { piano } & D R A N K & \text { (cat-piano-DRINK) }\end{array}$

Type of Ambiguity: Noun-Verb

Concordant priesters missen KERK (priests-masses/miss-CHURCH)

Discordant heimwee missen KERK (homesickness-masses/miss-CHURCH)

Neutral maattijd missen KERK

Unrelated heimwee maaltijd KERK

(meal-masses/miss-CHURCH)

(homesickness-meal-CHURCH)

Note. Target words are in capital letters.

condition, the first prime was unrelated to both second prime and target, but the target word was related to one meaning of the ambiguous word. Finally, in the unrelated condition. the three words were unrelated and unambiguous. For the complete set of materials, see Appendix $\mathrm{t}$.

For the set of noun-verb ambiguities both readings were equally represented by the targets. For eight items, the target was related to the verb reading. The remaining targets were related to the noun reading.

The test stimuli were arranged in two blocks. The first block contained the four priming conditions for the 16 noun-noun triplets. The second block contained all the priming conditions for the 16 noun-verb triplets (including $I$ adjective-verb triplet). In addition to the 64 word triplets, each block consisted of 32 triplets in which the target was a pronounceable nonword. In half of these nonword triplets, the first two words were unrelated and unambiguous (e.g.+ vogel-drank-GLEM; "bird-drink-GLEM"); in the other half, the first word was ambiguous and the second word was related to one of its meanings (e.g. kater-drankWELM; "(omcat/hangover-drink-WELM"), with both primes taken from the word triplets. Each nonword triplet appeared twice in the experimental session. In this way, the materials were constructed in exactly the same way as in the Milberg et al. study. Each target word was presented four times. To control for potentially confounding repetition effects, the order of the four priming conditions was counterbalanced among the word triplets. This was done by taking two random samples of 16 from the 24 possible condition orders, one for the block of noun-noun items, and one for the block of noun-verb items. These 16 orders were randomly assigned to the 16 critical word items per block. In addition, two instances of the same target word were separated by al least five other trials.

The full experiment thus had 256 experimental triplets, presented in two blocks of 128 . with 16 items per priming condition. Each block was preceded by 12 startup items. The experimental session began with a set of $\mathbf{2 0}$ practice items to familiarize the subjects with the task.

All materials were spoken by a female speaker in a sound-proof booth and recorded on a Revox A 700 tape recorder. The stimuli were digitized and stored in a VAX 750 computer with a sampling rate of $20 \mathrm{kHz}$. A speech wave form editing system was used to construct the triplets from the single words and nonwords. Identical words were represented by the same physical token. A trigger pulse was placed concurrent with the onset of each target. 
The ISI between the members of a triplet was $500 \mathrm{msec}$. There was a 4-sec silent interval between the triplets. Two test tapes were constructed, one with the noun-noun iterns, the other with the noun-verb items. In addition, a tape was made containing the set of practice items.

Apparatus. The apparatus for the experiment consisted of a Revox 877 stereo tape recorder, a Miro GD laboratory computer. a pulse-read unit, two pairs of Sennheiser HD 224 closed headphones (one for the subject and another for the experimenter), and a response keyboard with a YES button on the left side and a NO button on the right side. The lest stimuli on the left channel of the tape were played binaurally to the subject, while the trigger pulses on the right channel of the tape started a millisecond timer. The pulses were inaudible to the subjects. Reaction times and type of response (yes/no) were stored directly with the aid of the computer. The time-out was set to $5 \mathrm{sec}$. Latencies longer than $5 \mathrm{sec}$. were automatically stored as missing values.

Procedure. The subjects were lested individually in a single session, lasting approximately 60 min including a break of $10 \mathrm{~min}$ after the first block. Subjects were seated in a quiet room diagonally opposite the experimenter. with the keyboard placed in front of them.

Subjects were told that they would hear a series of tripiets either ending with a real Dutch word or ending with a nonword. They were instructed to respond to the third member of the triplet as quickly as possible. indicating whether it was a word by pressing the YES button or a nonword by pressing the NO button. For some patients the series of practice items had to be repeated to make sure that they undersiood the task. After the familiarization procedure, the subjects were asked to increase the speed of responding without losing accuracy. The emphasis on speed served the purpose of making the task as on-line as possible. No further feedback was given during the test session.

Due to the occurrence of hemiparesis or hemiplegia in a number of Broca palients, all patients were required to respond with their left index finger. Patients were instructed to place their left index finger on the YES bution and to move their finger to the NO button if they wanted to give a no response. This was done to speed up the reaction times for the more important yes responses and to avoid an increase in the error variance as a result of movements to be made from a starting position between the two buttons. To validate this procedure, half of the normal control subjects were required to react according to the same procedure, and the other half of the subjects were required to respond with the left index finger on the YES button and with the right index finger on the NO button.

At the end of the test session the experimenter interviewed the subjects about the salient features of the stimuli. This was done to find out whether subjects were aware of the presence of the ambiguous words.

\section{Results}

The results for the normal control subjects and the aphasic patients were analyzed separately. For the analyses on RT data, errors and missing values were replaced for every subject by his/her median per condition.

Only subject analyses will be reported. The reason is that the repetition effects caused by repeating target words four times form an improper source of error variance in the item analyses. For the interpretation of the results, the subject analyses are, therefore, most decisive. In all cases, Repeated Measures Analyses of Variance were performed, in which Subjects, Priming Condition with four levels (concordant, discordant, neutral, unrelated), and Type of Ambiguity with two levels (noun-noun am- 
biguity, noun-verb ambiguity) were completely crossed. Analyses of the latency data were performed on the subject medians for each condition. ${ }^{2}$ Analyses of the error data were done on the mean number of errors per subject by condition. Post-hoc comparisons used the Newman-Keuls procedure with a significance level of .05 (Winer, 1971).

Latency analyses. The results for the normal control subjects and both patient groups are summarized in Table 3.

To validate the response procedure that was used for the aphasic patients, an analysis of variance (ANOVA) was first done on the RT data of the normal controls with Response Procedure as additional factor. Six control subjects reacted with the left index finger, and six subjects used both index fingers. Most critical are the interactions of Response Procedure with Type of Ambiguity and Priming Condition. None of these interactions approached significance (Response Procedure by Type of Ambiguity: $F<1$; Response Procedure by Priming Condition: $F(3,30)=1.72$, $\mathrm{MS}_{c}=903, p=.18$ ). The main effect of Response Procedure was not significant either $\left(F(1,10)=3.29 . \mathrm{MS}_{\mathrm{c}}=3907 \mathrm{I}, p=.10\right)$. These results indicate that both response procedures were equally sensitive to the experimental manipulations. For further analyses, data were collapsed across response procedures.

The ANOVA on the latency data of the normal control subjects yielded a significant main effect of Type of Ambiguity $\left(F(1,11)=15.44, \mathrm{MS}_{\mathrm{e}}=\right.$ $2611, p<.005$ ). Latencies to noun-noun targets were on average $46 \mathrm{msec}$ shorter than those to noun-verb targets. Recall that different target words were used in the sets of noun-noun and noun-verb items. The main effect for Type of Ambiguity was mainly due to a difference in duration between the spoken noun-noun and noun-verb word targets. The spoken word forms for both target types had on average a durational difference of $56 \mathrm{msec}$. In a replication of the experiment using a visual presentation, the difference between noun-noun and noun-verb targets was no longer significant. The main effect of Type of Ambiguity is, therefore, trivial. As the main effects of this variable are of no concern to the central issues addressed, in the remainder these effects will not be reported.

Most importantly, the ANOVA for the control subjects also yielded a significant main effect of Priming Condition $\left(F(3,33)=12.57, \mathrm{MS}_{\mathrm{e}}=\right.$ $963, p<.0001)$. In addition, a significant interaction emerged between Type of Ambiguity and Priming Condition $\left(F(3,33)=6.37, \mathrm{MS}_{\mathrm{e}}=557\right.$, $\rho<.005$ ). Inspection of Table 3 reveals that this interaction was due to

\footnotetext{
${ }^{2}$ Individual RT distributions have a tendency to be skewed to the right. This tendency is even more pronounced in brain-damaged patients. Given the susceptibility of the sample mean to outjier effects, the sample median is a better estimate of the central tendency of the individual RT distribution. However, in addition to statistical analyses on the subject medians, analyses were also done on the subject means per condition. In no case did the pattern of results based on the means deviate from the reported pattern of results.
} 
TABLE 3

Means (Both across and by Type of Ambiguity) of the Median Auditory Lexical Decision Times as a Function of Priming Condition (ISI $=\mathbf{5 0 0} \mathrm{msec}$ )

\begin{tabular}{|c|c|c|c|c|c|c|}
\hline \multirow{2}{*}{$\begin{array}{l}\text { ISI = } 500 \text { msec } \\
\text { Priming condition }\end{array}$} & \multicolumn{2}{|c|}{ Overall } & \multicolumn{2}{|c|}{ Noun-Noun } & \multicolumn{2}{|c|}{ Noun-Verb } \\
\hline & RT & $d$ & RT & $d$ & RT & $d$ \\
\hline & \multicolumn{6}{|c|}{ Normal controls $(N=12)$} \\
\hline Concordant & 717 & 54 & 697 & 59 & 736 & * $\left[\begin{array}{ll}49 & 7\end{array}\right.$ \\
\hline Discordant & 751 & 20 & 713 & 43 & 789 & * -4 \\
\hline Neutral & 739 & 32 & 729 & $27] *$ & 750 & 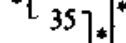 \\
\hline \multirow[t]{2}{*}{ Unrelated } & 771 & & 756 & & 785 & ]$\left.^{*}\right]$ \\
\hline & \multicolumn{6}{|c|}{ Broca's aphasics $(N=12)$} \\
\hline Concordant & 740 & 35 & 700 & 59 & 780 & 10 \\
\hline Discordant & 768 & 7 & 722 & 37 & 815 & -25 \\
\hline Neutral & 741 & 34 & 710 & $49]_{*}$ & 771 & 19 \\
\hline \multirow[t]{2}{*}{ Unrelated } & 775 & & 759 & & 790 & \\
\hline & \multicolumn{6}{|c|}{ Wemicke's aphasics $(N=5)$} \\
\hline Concordant & 856 & {$[80]$} & 839 & 56 & 874 & I03 \\
\hline Discordant & $938 *$ & {$[-2]$} & 897 & -2 & 980 & -3 \\
\hline Neutral & 923 & 13 & 871 & 24 & 976 & 1 \\
\hline Unrelated & 936 & & 895 & & 977 & \\
\hline
\end{tabular}

Note. Differences (d) are measured relative to the unrelated baseline. Significant differences between priming conditions in a Newman-Keuls test are marked by an asterisk. Where a significant interaction between Type of Ambiguity and Priming Condition was observed. Newman-Keuls tests were performed separately for noun-noun and noun-verb ambiguities.

different results in the discordant condition for both ambiguity types. Separate analyses of variance for the two types of ambiguity showed that the main effect of Priming Condition was significant for noun-noun ambiguities $\left(F(3,33)=8.05, \mathrm{MS}_{\mathrm{e}}=946, p<.0005\right)$, as well as for noun-verb ambiguities $\left(F(3,33)=13.99, \mathrm{MS}_{\mathrm{e}}=574, p<.0001\right)$.

The significant differences between priming conditions for both types of ambiguities are specified in Table 3. The normal control subjects showed facilitation for both types of ambiguity in the concordant and the neutral priming condition relative to the baseline. Facilitation in the discordant condition was obtained for the noun-noun items, but not for the noun-verb items.

Analyses of variance on the patient data did not include the data of the anomic patient. ${ }^{3}$ An ANOVA with Group of Patients as additional factor revealed a significant main effect for Group of Patients $(F(1,15)=4.63$,

\footnotetext{
${ }^{3}$ The results of the anomic patient were very much in agreement with those of the other patients. His overall median RTs per priming condition were as follows (in msec): $\mathbf{7 0 3}$ (concordant), 813 (discordant), 797 (neutral), 829 (unrelated).
} 
$\mathrm{MS}_{c}=151401, p<.05$ \}. The Broca's aphasics responded significantly faster than the Wernicke's aphasics. However, none of the interactions with the factor Group of Patients was significant. Most importantly, neither the interaction between Group of Patients and Priming Condition $\left(F(1,45)=2.17, \mathrm{MS}_{\mathrm{e}}=2717, p=.11\right)$ nor the Patient Group by Type of Ambiguity by Priming Condition interaction $\left(F(3,45)=1.37, \mathrm{MS}_{\mathrm{e}}\right.$ $2677, p=.27)$ approached significance. Before analyzing the data of both patient groups separately, a first analysis was, therefore, done on the pooled group data. ${ }^{4}$ This analysis showed a significant main effect of Priming Condition $\left(F(3,48)=5.82, \mathrm{MS}_{\mathrm{e}}=2915, p<.005\right)$. The interaction between Type of Ambiguity and Priming Condition, however, failed to reach significance $\left(F(3,48)=1.01, \mathrm{MS}_{\mathrm{e}}=2738, p=.39\right)$.

The significant overall priming effect was confirmed in separate ANOVAs for the two patient groups, which yielded a significant main effect of Priming Condition for both the Broca's $\left(F(3,33)=3.68, \mathrm{MS}_{\mathrm{e}}=2166\right.$, $p<.05)$, and the Wernicke's aphasics $\left(F(3,12)=3.52, \mathrm{MS}_{\mathrm{e}}=4234, p\right.$ $<.05$ ). The interaction between Type of Ambiguity and Priming Condition did not attain significance for the Wernicke patients $(F<1)$, but was marginally significant for the Broca patients $\left(F(3,33)=2.59, \mathrm{MS}_{\mathrm{e}}=\right.$ $1650, p=.069$ ).

Because of the marginally significant interaction between Type of Ambiguity and Priming Condition, the results of the Broca's aphasics were submitted to separate analyses for the noun-noun and the noun-verb items. The effect of Priming Condition was shown to be significant for both types of ambiguity (for noun-noun items: $F(3,33)=3.37, \mathrm{MS}_{\mathrm{c}}=$ $2362, p<.05$; for noun-verb items: $F(3,33)=2.94, \mathrm{MS}_{\mathrm{e}}=1454, p<$ .05).

In summary, both patient groups showed significant overall priming effects, with the largest amount of facilitation in the concordant priming condition, while no overall facilitation was obtained in the discordant priming condition.

Error analyses. The normal control subjects made errors on less than $1 \%$ of the critical word target trials. The group of Broca's aphasics made

\footnotetext{
"Given the limited size of especially the group of Wernicke patients (five patients in Experiment 1 and four in the remaining experiments), in a first analysis these patients were pooled with the Broca's aphasics, provided that no significant interaction between Patient Group and Priming Condition was obtained. The absence of this interaction indicates that there is no statistical reason to analyze both patient groups separately with respect to the effects of Priming Condition. The analysis of the pooled group data was primarily done to establish whether the overall priming effects reached significance and, as such, to determine the general sensitivity of the patients for the semantic context information contained by the primes. More fine-grained interpretations with respect to a possibly differential sensitivity to noun-noun and noun-verb ambiguities were based on separate analyses for both patient groups.
} 
errors on $2.1 \%$ of the word targets. The group of Wernicke patients had an error score of $7.7 \%$. The difference in error scores between the two patient groups was shown to be significant $\left(F(1,15)=4.77, \mathrm{MS}_{\mathrm{c}}=\right.$ $0.0179, p<.05$ ). Further analyses on the error data of the normal controls and both patient groups did not qualify the effects that were obtained for their respective latency data.

Introspective report. At the end of the test session subjects were interviewed about the experimental materials. All control subjects and all patients noted that target words were repeated. Eight control subjects remarked that the words in the triplets were sometimes semantically related. Seven Broca's aphasics and two Wernicke's aphasics also noted the occurrence of meaning relations between some of the words. Only two control subjects, and none of the patients, were aware of the fact that a subset of the materials consisted of words with different readings.

\section{Discussion}

For the normal control subjects the results of the concordant, the neutral, and the unrelated conditions are in agreement with the patterns of performance reported by Schvaneveldt et al. (1976), by Marcel (1980), and by Hagoort (1989). The strongest priming effects are obtained for the concordant condition, where both the first prime and the second prime are related to the target. In this case facilitation results from the combined effect of the relatedness of both primes with each other and with the target.

Quite unexpected, however, are the results for the discordant condition. These indicate a clear difference between the noun-noun and the noun-verb ambiguities. Whereas for the noun-verb ambiguities selective activation of the contextually appropriate meaning occurs, in the case of noun-noun ambiguities multiple activation of both the contextually biased and the nonbiased meaning is obtained.

The most likely explanation for the obtained difference between the two types of ambiguity is related to the difference in their representational make-up. Whereas noun-noun ambiguities only differ at the level of lexical-semantic representations, noun-verb ambiguities have an additional difference in their syntactic features. The presupposed locus of this difference is either at the level of form representations (Seidenberg et al., 1982) or at a separate level of representation specifying the grammatical form class associated with each meaning (Cottrell, 1988). Whatever the ultimate representational locus of the additional form class difference turns out to be, it might have provided the context with an extra source of information to effectuate the suppression of the contextually inappropriate reading. Thus, for noun-verb ambiguities probably two levels of representation contributed to the selection of the contextually appropriate 
meaning, by allocating attention to both the appropriate meaning and the appropriate form class. ${ }^{5}$

The results of the aphasic patients clearly differ from those in the Milberg et al. (1987) study. In contrast to Milberg et al., I failed to find an interaction between priming context and patient group. Not only Wer* nicke's aphasics, but also Broca's aphasics showed significant priming effects. The Broca's aphasics showed, at least for the noun-noun ambiguities, a pattern of results similar to that of the control subjects. That is, the absence of differential activation for the concordant and the discordant condition implies that no contextual selection of the appropriate noun reading has been taking place. In contrast, for the noun-verb ambiguities all subject groups had substantially shorter latencies in the concordant than in the discordant condition (although this difference just failed to reach significance in the Broca's aphasics), indicating a contextual selection effect for this type of ambiguity. In accordance with the results for the other two subject groups, the Wernicke patients had the shortest latencies in the concordant condition, indicating that the lexical context information could be used to activate the contextually appropriate meaning of the ambiguity.

Two aspects of the results of the aphasic patients deserve separate mention. First, again a clear semantic (associative) priming effect is established for a group of Wernicke patients. Together with the semantic priming effects obtained for Wernicke patients in a number of previous studies (Blumstein et al., 1982; Milberg \& Blumstein, 1981; Milberg et al., 1987, 1988), this result supports the claim that the lexical-semantic deficits typically found in Wernicke's aphasia (Goodglass \& Baker, 1976; Whitehouse et al., 1978; Zurif et al., 1974) are not so much due to a structural impairment of the lexical-semantic network, but rather to the inability to operate on lexical-semantic information after it has been accessed.

Second, the discrepancy between the results of the Broca patients reported by Milberg et al. (1987) and those obtained in this study needs to be clarified. In contrast to the present study, Milberg et al, did not obtain a significant overall priming effect. In fact, the Broca patients in their study showed the longest latencies in the concordant and the shortest latencies in the discordant condition. Milberg et al. (1987) suggest that the absence of a priming effect for their Broca's aphasics might indicate a deficit in the automatic access to lexical-semantic information. If this

\footnotetext{
'In contrast to the group of elderly control subjects, a group of young, highly educated subjects tested in the same experiment showed selective activation of the contextually appropriate meaning for the noun-noun ambiguities. These younger subjects did not seem to need the additional form class information for rapidly selecting the appropriate and suppressing the inappropriate reading.
} 
explanation is correct. one way to explain the different outcomes of both studies is by assuming that in Broca's aphasics the degree of severity of their aphasia is correlated with the degree of impairment in automatically accessing lexical-semantic information. Possibly the Broca's aphasics in the Milberg et al. study differ in the degree of severity from the patients in my study, with the latter ones having a less severe aphasia. One piece of evidence supporting this suggestion is the difference in the overall latencies of the patients' responses in both studies. The Broca's aphasics in this study were much faster (on average $650 \mathrm{msec}$ ) than the Broca patients in the Milberg et al. study. Even taking into account that the response procedure and the request for speed in the instruction of Experiment 1 contributed to the relatively fast responses, the remaining difference in the response latencies is still substantial. In as far as this latency difference indicates a difference in the degree of severity between the groups of Broca patients in both studies, it might be the case that with an ISI of $500 \mathrm{msec}$ the deficit in the automatic processing of ambiguous words reveals itself only in the most severely impaired group of patients. This implies that a possible deficit in the automatic processing of lexicalsemantic information is expected to show up in the relatively less impaired group if the task conditions tap the automatic spread of activation more strongly than in Experiment 1.

\section{EXPERIMENT 2}

One way to increase the contribution of ASA to the priming effects is by reducing the ISI between the members of the triplets. Therefore, I decided to do a second experiment with the same materials and the same patients, but with the ISI reduced to $100 \mathrm{msec}$. Aphasic patients with an impairment in the automatic access of lexical-semantic information are expected to show no, or at least reduced, priming effects with an ISI of $100 \mathrm{msec}$.

\section{Method}

Subjects. A group of 12 elderly right-handed subjects from the MPl subject pool served as the normal controls. None of these subjects had participated in Experiment 1 . The control subjects were matched in age and education with the aphasic patients. The mean age for the group of normal control subjects was 59.8 years (range 46-72). A group of 11 aphasic patients participated in this experiment. Seven patients were diagnosed as Broca's aphasics, four patients as Wernicke's aphasics. The Broca's aphasics had a mean age of $\$ 2.8$ years. the Wernicke's aphasics had a mean age of 70.5 years. This group of 11 patients also participated in Experiment I (see Table I). Seven of the patients participating in Experiment 1 were no longer available. The time interval between the test sessions of Experiment 1 and Experiment 2 was at least 4 months.

Marerials. The same digitized tokens as in Experiment I were used to construct two new test tapes and a new practice tape. The only difference with the tapes of Experiment 1 was the interval of silence between the members of a triplet. With the help of a speech waveform 
editing system, the 1 I I was reduced to 100 msec. There was a 4-sec interval of silence between the triplets.

Procedure. The procedure was the same as in Experiment 1, with one minor change. In Experiment 1, it was demonstrated that responding with one or two fingers made no difference for the results on the word targets. Therefore, in Experiment 2 the normal control subjects and the patients with complete control of both hands were instrucled to place their left index finger on the YES button and their right index finger on the NO button. Aphasic patients with control of their left hand only were required to place their left index finger on the YES button. They were instructed to press the YES button as quickly as possible if they heard a word and to move their finger to the NO button and press it if they heard a nonword.

\section{Results}

Table 4 summarizes the results for the normal controls, the Broca's aphasics, and the Wernicke's aphasics.

Latency analyses. The ANOVA on the latency data of the control subjects yielded a significant effect of Priming Condition $(F(3,33)=$ $\left.25.72, \mathrm{MS}_{\mathrm{e}}=615, p<, 0001\right)$. The analysis also showed a significant interaction between Type of Ambiguity and Priming Condition $(F(3,33)$ $\left.=5.24, \mathrm{MS}_{\mathrm{e}}=679, p<.005\right)$. Again, the discordant condition was

TABLE 4

Means (Both across and by Type of Ambiguity) of the Median Auditory Lexical Decision Times as a Function of Priming Condition (ISI $=100 \mathrm{msec}$ )

\begin{tabular}{|c|c|c|c|c|c|c|}
\hline \multirow{2}{*}{$\begin{array}{l}\text { ISI = } 100 \text { msec } \\
\text { Priming condition }\end{array}$} & \multicolumn{2}{|c|}{ Overall } & \multicolumn{2}{|c|}{ Noun-Noun } & \multicolumn{2}{|c|}{ Noun-Verb } \\
\hline & RT & $d$ & RT & $d$ & RT & $d$ \\
\hline & \multicolumn{6}{|c|}{ Normal controls $(N=12)$} \\
\hline Concordant & 665 & 49 & 637 & 59 & 693 & 40 \\
\hline Discordant & 718 & -4 & 671 & 25 & 764 & $\mid-31$ \\
\hline Neutral & 682 & 32 & 657 & $39]_{*}$ & 706 & $*\left[\begin{array}{ll}27 \\
2\end{array}\right] *$ \\
\hline \multirow[t]{2}{*}{ Unrelated } & 714 & & 696 & & 733 & \\
\hline & \multicolumn{6}{|c|}{ Broca's aphasics $(N=7)$} \\
\hline Concordant & 829 & 68 & 764 & 1317 & 894 & 4 \\
\hline Discordant & 879 & 18 & 849 & 46 & 909 & -11 \\
\hline Neutral & 834 & 63 & 785 & $110]$ & 884 & 14 \\
\hline \multirow[t]{2}{*}{ Unrelated } & 897 & & 895 & & 898 & \\
\hline & \multicolumn{6}{|c|}{ Wernicke's aphasics $(N=4)$} \\
\hline Concordant & 843 & {$[72]$} & 827 & 96 & 859 & 48 \\
\hline Discordant & 909 & "[ 6 ]. & 868 & 55 & 949 & -42 \\
\hline Neutral & 871 & $44^{*}$ & 877 & 46 & 865 & 42 \\
\hline Unrelated & 915 & & 923 & & 907 & \\
\hline
\end{tabular}

Nofe. Differences $(d)$ are measured relative to the unrelated baseline. Significant differences between priming conditions in a Newman-Keuls test are marked by an asterisk. Where a significant interaction between Type of Ambiguity and Priming Condition was observed, Newman-Keuls tests were performed separately for noun-noun and noun-verb ambiguities. 
mainly responsible for this interaction. Separate analyses for the two ambiguity types showed that the effect of Priming Condition was signifcant for noun-noun ambiguities $\left(F(3,33)=10.11, \mathrm{MS}_{e}=737, p=\right.$ $.0001)$, as well as for noun-verb ambiguities $\left(F(3,33)=21.40, \mathrm{MS}_{\mathrm{e}}=\right.$ $557, p<.0001$ ).

As in Experiment I, the normal control subjects showed the largest amount of facilitation in the concordant priming condition. Again, the discordant condition yielded a different pattern of results for the two types of ambiguity. Relative to the baseline, this condition resulted in facilitation for the noun-noun items, but in inhibition for the noun-verb items.

Patient data showed the same profile as the data of the normal controls, in that relative to the baseline the discordant condition had shorter latencies for the noun-noun ambiguities and longer latencies for the nounverb ambiguities. The ANOVA on the latency data of the aphasic patients with Group of Patients as an additional factor did not obtain a significant main effect for Group of Patients $(F<1)$. Both the Group of Patients by Priming Condition interaction $(F<1)$ and the Group of Patients by Type of Ambiguity by Priming Condition interaction $\left(F(3,27)=1.65, \mathrm{MS}_{\mathrm{e}}=\right.$ $3109, p=.20$ ) failed to approach significance. A first ANOVA was therefore performed on the pooled group data. It yielded a significant effect of Priming Condition $\left(F(3,30)=10.86, \mathrm{MS}_{\mathrm{e}}=2221, p=.0001\right)$. The interaction between Type of Ambiguity and Priming Condition was marginally significant $\left(F(3,30)=2.84, \mathrm{MS}_{\mathrm{e}}=3311, p=.054\right)$.

Inspection of the patient data suggested that the overall priming effect in the Broca's aphasics was mainly due to the noun-noun ambiguities. An ANOVA on their latency data yielded a significant effect of Priming Condition $\left(F(3,18)=5.86, \mathrm{MS}_{\mathrm{e}}=2647, p<.01\right)$. However, this effect was qualified by a marginally significant Type of Ambiguity by Priming Condition interaction $\left(F(3,18)=2.93, \mathrm{MS}_{\mathrm{e}}=3563, p=.06\right)$. Separate analyses for the two ambiguity types revealed that the effect of Priming Condition was significant for the noun-noun ambiguities $(F(3,18)=$ $\left.11.94, \mathrm{MS}_{\mathrm{e}}=2110, p<.0005\right)$. but not for the noun-verb ambiguities $(F<1)$.

An ANOVA on the latency data of the Wernicke's aphasics also yielded a significant main effect of Priming Condition $(F(3,9)=4.78$, $\left.\mathrm{MS}_{\mathrm{e}}=1919, p<.05\right)$. Although the data suggested a different result in the discordant condition for the two ambiguity types, the Type of Ambiguity by Priming Condition interaction failed to reach significance $(F(3$. 9) $=1.86, \mathrm{MS}_{\mathrm{e}}=2202, p=.21$ ).

In summary, both patient groups again showed a significant overall priming effect, which in the Broca's aphasics was mainly due to the noun-noun ambiguities.

Error analyses. The normal control subjects made errors on only $1 \%$ 
of the critical word target trials. The group of Broca's aphasics had an overall error score of $3.2 \%$ on the word targets. For the group of Wernicke patients the error score was $6.8 \%$. This difference was not signifcant $\left(F(1,9)=I .03, \mathrm{MS}_{\mathrm{e}}=0.0257, p=.34\right)$. For the noun-verb items a significant main effect for Priming Condition was obtained, which was mainly due to the relatively high error percentage for the neutral priming condition $\mathbf{9 . 8 \%}$ for the Broca's aphasics; $10.9 \%$ for the Wernicke's aphasics). A post-hoc Newman-Keuls test on the mean number of errors for the noun-verb items in the four priming conditions showed that the neutral condition differed from all the other conditions. The reason for this relatively high error score of the neutral priming condition is unclear. It implies, however, that the relatively fast reaction times to noun-verb targets in the neutral condition should be interpreted with some caution, because of a possible speed-accuracy trade-off.

\section{Discussion}

The normal control subjects showed essentially the same pattern of results as in Experiment 1. That is, for the noun-noun ambiguities multiple activation of both meanings was again obtained, while the noun-verb ambiguities showed activation for the contextually appropriate reading only. The inhibition obtained for the discordant noun-verb triplets relative to the unrelated baseline might have been caused by a postlexical semantic matching process, in which attention is allocated to the biased meaning, with the inhibition of the unbiased meaning as its concomitant result (cf. Simpson, 1984). De Groot (1984) has argued that semantic matching can be effective at short prime-target intervals.

The overall priming pattern for both patient groups does not differ substantially from that of the normal controls. Again no interaction between the groups of Broca's and Wernicke's aphasics has been obtained. Both patient groups showed a clear overall priming effect. ${ }^{6}$

This result is strong evidence against the claim by Milberg et al. (1987)

\footnotetext{
- A comparison between the results of the II patients who participated both in Experiment $I$ and in Experiment 2 suggests that priming effects were even stronger at the short ISl of $100 \mathrm{msec}$. This suggestion is based on the larger overall $F$ values and the larger mean squares for the priming conditions (MSpc) obtained with an ISI of $100 \mathrm{msec}$. Comparing the results at the ISI of 100 and $500 \mathrm{msec}$ led to the following outcomes for the group of 11 aphasic patients: $I S I=100 \mathrm{msec}: F(3,30)=10.86$. MSpc $=241[8 \div 1 S 1=500$ msec: $F(3$. $30)=3.78, \mathrm{MSpc}=12479$. For the group of Broca patients, who are claimed to have an impairment in automatic lexical-semantic processing, the following results were obtained: $\mid S I=100$ msec: $F(3,18)=5.86 . \mathrm{MSpc}=15523 ; \mathrm{ISI}=500 \mathrm{msec}: F(3,18)=2.54$, $\mathrm{MSpc}=5748$. Although one has to be very cautious in interpreting differences in $F$ ratios, nevertheless, the conclusion seems warranted that the priming effects are certainly not weakened by reducing the ISI. and thereby increasing the contribution of automatic lexical processing.
} 
that Broca's aphasics have a specific impairment in the automatic processing of lexical-semantic information. If automatic access to lexicalsemantic representations had been selectively impaired in Broca's aphasia, the reduction of the ISI to $100 \mathrm{msec}$ should have led to a decrease in the priming effects, since it is generally assumed that at shorter ISIs the effects of ASA are stronger. Despite the increased contribution of ASA to the obtained priming effects at the ISI of $100 \mathrm{msec}$ compared to Experiment 1 with an ISI of $500 \mathrm{msec}$, no evidence for a reduction in the effects of priming was obtained. The significant priming effects at the shorter ISI, which more heavily relies on ASA, indicate that the deficits in lexical-semantic processing of both Broca's and Wernicke's aphasics cannot be attributed to a substantial impairment in the automatic access of lexical-semantic information.

With respect to Broca's aphasics, Experiment 2 did not resolve the discrepancy between the presence of an overall priming effect in this study and the absence of such an effect in the study by Milberg and his colleagues. Another possible explanation for the discrepancy between both studies is that for some reason the priming effects in Broca patients are shorter lived than in the unimpaired language processing system. In that case priming effects should decrease or disappear completely with longer ISIs. Whereas the priming effects of the supposedly more severe Broca patients in the Milberg et al. study already had disappeared with an ISI of $500 \mathrm{msec}$, the less severe patients in this study might lose their priming effects with a substantially longer ISI. To test this possibility, in Experiment 3 the ISI was increased to $1250 \mathrm{msec}$.

In addition to the overall priming effects for both patient groups, two other aspects of the results for the Broca's aphasics should be mentioned. First, the Broca's aphasics showed a clear difference in the size of the priming effects for noun-noun and noun-verb ambiguities. Compared to the strong priming effect for the noun-noun ambiguities, the absence of a priming effect for the noun-verb ambiguities is remarkable. Whereas the normal controls and the Wernicke's aphasics showed a large latency difference between the concordant and the discordant noun-verb triplets, this difference for the Broca's aphasics was only $15 \mathrm{msec}$. This suggests that the Broca's aphasics benefit less or not at all from the form class difference between both readings of the ambiguity. In the general discussion I will come back to possible explanations for this dissociation in the priming effects for noun-noun and noun-verb ambiguities.

The Broca's aphasics differed from the Wernicke's aphasics and the control subjects in another respect. Whereas both normal controls and Wernicke's aphasics had shorter latencies in this experiment compared to those in Experiment 1, the Broca's aphasics were substantially slower. The seven Broca's aphasics participating in both experiments were on average $95 \mathrm{msec}$ slower with the ISI of $100 \mathrm{msec}$ than with the ISI of 500 
msec ( 860 and $765 \mathrm{msec}$, respectively). This difference was significant on a $t$ test $(t=2.84, p<.05)$. Whereas the higher rate of presentation induced an increase in the speed of responding in the control subjects and in the Wernicke's aphasics, it caused a decrease in the response speed of the Broca's aphasics. One might speculate that an increase in the processing load associated with the perceptual identification (cf. Humphreys, 1985) and the semantic integration of the three words within the shorter time frame imposed by Experiment 2 is responsible for this delayed responding. Recent findings from another on-line study with Broca's aphasics also suggest a dramatic slowing down of lexical decisions as a consequence of an increase in the processing load (Friederici \& Kilborn, 1989; the authors, however, give a different explanation for their results).

\section{EXPERIMENT 3}

In Experiment 3 the ISI between the members of the triplets was increased to $1250 \mathrm{msec}$. Apparatus and procedure were exactly the same as in Experiment 2.

\section{Method}

Subjects. The same group of 11 aphasic patients as in Experiment 2 and another group of 12 right-handed normal control subjects participated in Experiment 3. The normal controls were approximately matched in age and education with the aphasic patients. The mean age of the control subjects was 62.6 years (range $48-71$ ). None of the control subjects had participated in the preceding experiments. The time interval for the aphasic patients between the test sessions of Experiment 2 and Experiment 3 was at least four weeks. Apparaus and procedure were the same as in Experiment 2.

Materials. Three new tapes were constructed, two test tapes and one practice tape. They only differed from the tapes of the previous experiments in the interval of silence between the members of the triplets. With the help of a speech waveform editing system the interval was increased to $1250 \mathrm{msec}$. The interval of silence between the triplets was again $4 \mathrm{sec}$.

\section{Results}

Results were analyzed as in the Experiments 1 and 2. A summary of the results is given in Table 5 .

Latency analyses. For the group of normal controls the ANOVA yielded a significant main effect of Priming Condition $(F(3,33)=22.89$, $\mathrm{MS}_{\mathrm{c}}=769, p<.0001$ ). The overall priming effect was again qualified by a significant interaction between Type of Ambiguity and Priming Condition $\left(F(3,33)=4.92, \mathrm{MS}_{e}=947, p<.01\right)$. Separate ANOVAs were therefore performed for the two ambiguity types. These revealed a significant effect of Priming Condition for both types of ambiguity (for the noun-noun ambiguities: $F(3,33)=7.40, \mathrm{MS}_{e}=1088, p<.001$; for the noun-verb ambiguities: $F(3,33)=22.63, \mathrm{MS}_{\mathrm{e}}=628, p<.0001$ ). 
TABLE 5

Means (Both across and by Type of Ambiguity) of the Median Auditory Lexical Decision Times as a Function of Priming Condition (IS $1=1250 \mathrm{msec}$ )

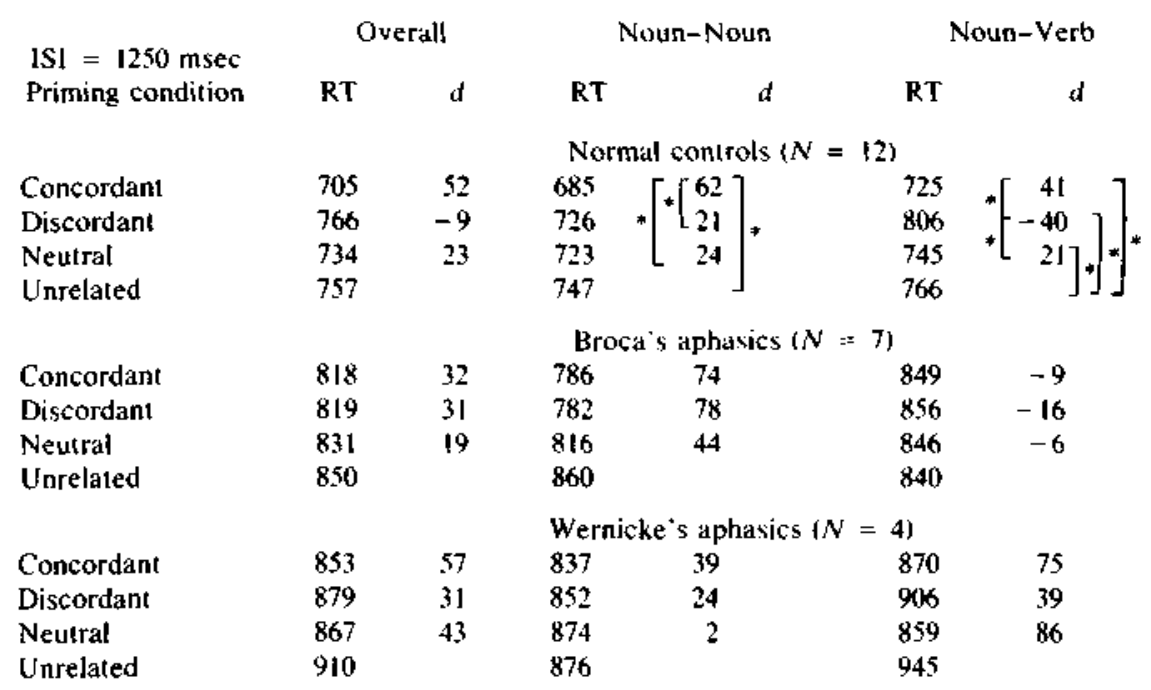

Note. Differences $(d)$ are measured relative to the unrelated baseline. Significant differences between priming conditions in a Newman-Keuls test are marked by an asterisk. Where a significant interaction between Type of Ambiguity and Priming Condition was observed. Newman-Keuls tesis were performed separately for noun-noun and noun-verb ambiguities.

For the normal control subjects the shortest latencies were again obtained in the concordant condition. In the discordant condition, nounverb items showed inhibition relative to the baseline, while noun-noun items showed a nonsignificant facilitatory trend.

The ANOVA on the latency data of the patients with Group of Patients as additional factor did not yield a significant main effect of Group of Patients $(F<1)$ and, more importantly, did not yield a significant interaction between Group of Patients and Priming Condition $(F<1)$. A significant Group of Patients by Type of Ambiguity by Priming Condition interaction was also not observed $\left(F(3,27)=2.21, \mathrm{MS}_{\mathrm{e}}=2155, p=.11\right)$. The ANOVA on the pooled group data did not yield a significant effect of Priming Condition $\left(F(3,30)=2.46, \mathrm{MS}_{\mathrm{e}}=2795, p=.082\right)$, indicating that compared to the shorter ISIs a stable priming effect was no longer obtained. The interaction between Type of Ambiguity and Priming Condition failed to reach significance $\left(F(3,30)=1.71, \mathrm{MS}_{\mathrm{e}}=2416, p=.19\right)$.

Inspection of the patient data revealed that for the Broca's aphasics the size of the priming effects again seemed much larger for the noun-noun ambiguities than for the noun-verb ambiguities. An ANOVA on the la- 
tency data of these subjects did not yield a significant effect of Priming Condition $(F<1)$. However, the interaction between Type of Ambiguity and Priming Condition reached significance $\left(F(3,18)=3.34, \mathrm{MS}_{\mathrm{e}}=\right.$ $1858, p<.05$ ). Separate analyses for the two types of ambiguity showed a marginally significant effect of Priming Condition for the noun-noun ambiguities $\left(F(3,18)=2.77, \mathrm{MS}_{\mathrm{e}}=3283, p=.072\right)$, but no significant priming effect for the noun-verb ambiguities $(F<1)$. A Newman-Keuls test did not result in significant differences for the noun-noun ambiguities between the four priming conditions.

An ANOVA on the latency data of the Wernicke's aphasics showed that neither the effect of Priming Condition $\left(F(3,9)=2.63, \mathrm{MS}_{\mathrm{e}}=1799\right.$, $p=.11)$ nor the interaction between Type of Ambiguity and Priming Condition $(F<1)$ approached significance.

In summary, neither of the two patient groups showed a significant overall priming effect, and once again an interaction between patient group and priming context could not be established.

Error analyses. Normal control subjects had an overall error percentage on the word targets of less than $1 \%$. The Broca's aphasics had an overall error percentage of $3.1 \%$ on the word targets. For the Wernicke's aphasics, the overall error score was $5.3 \%$. The difference between both patient groups was not significant. The results of the analyses on the error data did not further qualify the latency results.

\section{Discussion}

The group of normal controls showed the same pattern of results as found in Experiment 2. Although the latency difference between the discordant and the unrelated noun-noun triplets just failed to reach significance, the trend of multiple activation for the noun-noun ambiguities is consistent with the results of the two previous experiments. For the noun-verb ambiguities significant inhibition was again obtained in the discordant condition, indicating the contribution of controlled processing to the priming effects. As in the previous experiments the largest amount of facilitation emerged in the concordant condition for both noun-noun and noun-verb items.

The results for the aphasic patients differed from the two previous experiments in that with an ISI of $1250 \mathrm{msec}$ a significant priming effect was no longer obtained. Although the overall trend of the results is in the same direction as in Experiment 2, the priming pattern is no longer stable at this relatively long ISI. This, again, holds equally for both types of patients. It indicates that in the groups of Broca's and Wernicke's aphasics as a whole, priming effects are shorter lived than in normal control subjects. Increasing the ISI between the words of the target triplets has resulted in a shift from highly significant overall priming effects at 100 
msec to nonsignificant priming effects at $1250 \mathrm{msec}$. This suggests that in these aphasic patients either the automatic spread of activation shows a faster decay or the controlled processing of lexical-semantic information is impaired. I will come back to these different explanations in the general discussion.

Finally, the absence of an interaction between priming context and group of aphasic patients in the three priming experiments is in clear contrast with the results of studies in which aphasic patients are required to make explicit semantic judgements (Goodglass \& Baker, 1976; Whitehouse et al., 1978; Zurif et al., 1974). In these studies, Wernicke patients are consistently reported to perform worse than Broca's aphasics. To test whether this pattern of results could be replicated with the same Wernicke's and Broca's aphasics who participated in the previous three experiments, Experiment 4 tested these patients with an explict semantic judgement task.

\section{EXPERIMENT 4}

This experiment is done to test whether a completely different task with a subset of the materials used in Experiments 1 to 3 results in a different pattern of performance for the two patient groups. In Experiment 4 subjects are explicitly asked to give their judgements as to whether the words in auditorily presented word pairs go together semantically or not. The experimental word pairs consist of the first two words of the concordant, discordant, and neutral triplets forming the primes in the lexical decision experiments. The priming effects in Experiments 1 and 2 were attributed to the effects of the prime contexts, which consisted of the first two words of the triplets. As indicated by the results of the previous experiments, the semantic information specified in the lexical entries of these words could be accessed in an implicit way. However, this does not necessarily mean that the same items can be elaborated on in an explicit memory task. This experiment is done to test how accurate patients are under task aspects which require them to explicitly judge the semantic aspects of the materials.

\section{Method}

Subjects. Eight elderly subjects from the MPI subject pool served as the normal controls. The control subjects were approximately matched in age and education with the aphasic patients. The same group of seven Broca's aphasics and four Wernicke's aphasics that participated in Experiments 1, 2, and 3 was tested. The time interval between the test sessions of Experiment 4 and the previous experiments was at least 4 weeks.

Materials. The materials for this experiment were selected from the materials used in the previous experiments. Twenty of the 32 ambiguous words were used. They consisted of all the noun-noun ambiguities and four noun-verb ambiguities (three of which were in the citation form for both the noun and the verb reading). The critical word pairs were created 
from the first two words of the triplets in the previous experiments. For each ambiguous word two related word pairs were constructed, one for each reading (e.g., kater-bier; "(omcat/hangover-beer"; poes-kater; "cat-toncat/hangover"). In addition, three unrelated word pairs were created. One contained the two primes from the neutral priming condition (e.g.. piano-kater; "piano-tomcat/hangover"). The other two were constsucted by combining the unambiguous first primes (e.g., bier-piano; "beer-piano"; bier-poes; "beer-cat"). These latter pairs served as fillers to prevent the development of strategies based on the repetition of ambiguous words. This resulted in a total number of 100 word pairs, 40 related and 60 unrelated. In addition, eight word pairs were constructed to be used as practice items.

A test tape was constructed using the same lokens as in the previous experiments. The test tape presented the word pairs in a randomized sequence, with the constraint that word pairs sharing one word were separated by at least four other word pairs. The interval of silence between the two members of a word pair was $500 \mathrm{msec}$.

Apparatus. The apparatus for Experiment 4 consisted of a Uher 4400 tape recorder and two pairs of Sennheiser HD 224 closed headphones fone for the subject and another for the experimenter).

Procedure. Subjects were tested individually during one session. They were told that they would hear a series of word pairs, some of which consisted of two words that were in some way related in meaning, and others consisting of two words that were unrelated in meaning. Subjects were required to indicate for every word pair whether the two words went together semantically, by pointing to a card saying YES, or whether the two words were unrelated in meaning, by pointing to a card saying NO. After every word pair, the experimenter stopped the tape, wrote down the subject's response, and started the tape recorder again to present the next pair to the subject. No feedback was given to the subjects during the presentation of the experimental word pairs.

\section{Results}

Only the responses to the word pairs derived from the concordant, discordant, and neutral triplets of the previous lexical decision experiments were scored (40 related and 20 unrelated pairs). To separate the subject's sensitivity to the semantic relations from his/her response bias, the nonparametric index of sensitivity, $A^{\prime}$, was computed for each subject. This measure is derived from signal-detection analysis (Green \& Swets, 1966; Grier, 1971). The $A^{\prime}$ value $($ e.g., 0.90$)$ can be interpreted as the expected score of that percentage correct (e.g., 90\%) on a forced two-choice procedure (Linebarger, Schwartz, \& Saffran, 1983). The $A$ 's for the individual subjects are given in Table 6.

Because the means and variances are correlated for $A^{\prime}$ scores, they were first submitted to an arcsin transformation (Winer, 1971). The transformed data were entered into an ANOVA with Group of Subjects (Normal Controls, Broca's Aphasics, Wernicke's Aphasics) as the only factor. The analysis yielded a significant effect for Group of Subjects $(F(2,16)$ $\left.=8.26, \mathrm{MS}_{\mathrm{e}}=52.7, p<.005\right)$. The group of normal controls showed the highest mean $A^{\prime}$ score $(0.89)$. The mean score of the group of Broca's aphasics $(0.82)$ was higher than that of the Wernicke's aphasics (0.72). A post-hoc Newman-Keuls test showed that the group of Wernicke pa- 
TABLE 6

$A^{\prime}$ Scores for the Individual Subjects, and Means per Group of Subjects in the Semantic Judgement Task

\begin{tabular}{lccccccccc}
\multicolumn{1}{c}{ Subjects } & 1 & 2 & 3 & 4 & 5 & 6 & 7 & 8 & $\bar{X}$ \\
Normal controls & 0.82 & 0.93 & 0.87 & 0.87 & 0.87 & 0.95 & 0.93 & 0.91 & 0.89 \\
Broca's aphasics & 0.92 & 0.90 & 0.79 & 0.70 & 0.90 & 0.72 & 0.78 & & 0.82 \\
Wernicke`s aphasics & 0.81 & 0.69 & 0.65 & 0.74 & & & & & 0.72
\end{tabular}

Note. The subject numbers of the aphasic patients correspond to the order in which they are listed in Table $\mathbf{I}$.

tients had a significant lower score than both the Broca's aphasics and the normal controls. The scores of the Broca's aphasics and the normal controls, however, did not differ significantly.

\section{Discussion}

Although their performance was above chance, the Wernicke's aphasics showed a clear deficit in explicitly judging the semantic relations between words. This result is in agreement with the findings obtained in previous studies which required the patients to make semantic judgements of some sort (e.g., Goodglass \& Baker, 1976; Whitehouse et al. 1978: Zurif et al., 1974). However, the same word pairs that were used for the semantic judgements, induced the priming effects obtained for these patients in Experiments I and 2. Moreover, whereas the Wernicke's aphasics and the Broca's aphasics did not differ in their overall pattern of results in the priming experiments, the two groups of patients showed a difference in the semantic judgement task. This dissociation of results indicates that the semantic deficits in Wernicke's aphasia are not so much due to a deficit in automatically accessing the mental lexicon, but to an impairment in operating on the lexical-semantic information in explicit memory tasks.

The qualitative differences in the results obtained with different tasks in normal subjects (e.g., Graf \& Mandler, 1984), and the patterns of dissociation seen in a range of neuropsychological disorders, such as prosopagnosia, alexia, Korsakoff's syndrome, or blindsight (e.g., Renault, Signoret, Debruille, Breton, \& Bolgert, 1989; Shaltice \& Saffran, 1986; Verfaellie. Cermak, Blackford, \& Weiss, 1990; Volpe, LeDoux, \& Gazzaniga, 1979; Weiskrantz, 1986), have documented the differences between implicit and explicit memory (see Schacter, 1987). Although it is still an unsettled issue whether implicit and explicit memory refer to different retrieval mechanisms (e.g., automatic vs. controlled processing) or to different underlying systems (e.g., procedural vs. declarative memory; Squire \& Cohen, 1984), a growing body of data suggests that the 
distinction is useful (Schacter, 1987). Explicit memory is revealed when subjects are required to consciously elaborate on materials accessed in memory (Graf \& Mandler, 1984). In contrast to access, elaborative processing is claimed to require considerable attentional resources (Graf \& Mandler, 1984).

It is in experiments tapping this explicit memory that Wernicke's aphasics show their semantic deficits. This suggests that the comprehension impairments of these patients are not caused by a deficit in accessing the mental lexicon, but might arise in the postlexical process of integrating/ elaborating the lexical-semantic information into a higher order message representation (see also Milberg \& Blumstein. 1981).

In the process of language understanding the elaboration of materials accessed in semantic memory (e.g., necessary for the construction of a message representation of the utterance in the context of the current discourse) is normally done by integrating the semantic information into an episodic memory representation of the message and its context. Although the distinction between semantic and episodic memory is not very clear-cut, and although the evidence for this distinction is still a matter of debate (see Tulving, 1984, 1987), it nevertheless seems to cover the broad distinction between the mental lexicon (a subset of semantic memory) as "a repository of declarative knowledge about the words of [the speaker/hearer's] language" (Levelt, 1989; p. 182) and the discourse model as part of the person's episodic memory.

The lexical decision experiments reported above allow us to test whether the impairment of the Wernicke patients in semantic tasks requiring explicit semantic judgements is due to a deficit in forming episodic traces. This can be done by looking at the repetition effects for the target words. During the test session the target words were repeated four times. It has been claimed that delayed repetition effects demonstrate that subjects have formed an episodic memory trace on the basis of the previous presentation of the words (Evett \& Humphreys, 1981; Feustel, Shiffrin, \& Salasoo, 1983; Humphreys, 1985). The effects of repetition priming have been shown to be independent of the lexical activation processes involved in semantic priming (Den Heyer, Goring. \& Dannenbring, 1985). At the same time, repetition priming is one of the most widely used measures in tapping implicit memory (Tulving \& Schacter, 1990). The repetition effects in the present priming study thus allow us to answer the question whether the Wernicke's aphasics have a deficit in forming episodic memory traces or an independent and specific impairment in consciously operating on automatically accessed lexical-semantic information.

To test the effects of repetition priming for the control subjects and for the 11 aphasic patients who participated in the three lexical decision experiments, the data of Experiments 1 to 3 were taken together. Table 7 
summarizes the results for the control subjects and the two aphasic patient groups.

For all three subject groups significantly longer latencies were obtained on the first presentation than on all the following presentations. The differences between second, third, and fourth presentation were not significant in a Newman-Keuls test. So, it can be concluded that the Wernicke's aphasics showed the same repetition effects as the Broca's aphasics and the normal control subjects.

This result suggests that the impairment which Wernicke patients show in consciously operating on lexical-semantic information cannot be attributed to a deficit in forming episodic memory traces.

\section{GENERAL DISCUSSION}

The aim of this study was to test recent claims about impairments in either automatic or controlled processing of lexical-semantic information in Broca's and Wernicke's aphasia (Blumstein et al., 1982; Milberg \& Blumstein, 1981; Milberg et al., 1987). The resolution of lexical ambiguity in a word priming context served as the vehicle to study possible deficits in accessing lexical meanings in a group of aphasic patients.

With respect to the processing of ambiguous words in a word context, it has been claimed that initially all meanings of an ambiguous word are accessed automatically (Holley-Wilcox \& Blank, 1980; Simpson, 1984; Marcel, 1980). After the initial access of the different meanings, the context is used to select the appropriate reading. According to Tanenhaus, Leiman, and Seidenberg (1979), the resolution of lexical ambiguity can be characterized as a veiled controlled process. Shiffrin and Schneider (1977) divided controlled processes into two classes: veiled and accessible. In contrast to the accessible controlled processes, the veiled con-

TABLE 7

Means (Collapsed over the ISIs in Experiments 1, 2, and 3) of the Median Auditory Lexical Decision Times as a Function of Index of Presentation

\begin{tabular}{|c|c|c|c|c|c|c|}
\hline \multirow[b]{2}{*}{ Index of presentation } & \multicolumn{2}{|c|}{$\begin{array}{l}\text { Normal controls } \\
\qquad(N=36)\end{array}$} & \multicolumn{2}{|c|}{$\begin{array}{c}\text { Broca's aphasics } \\
(N=7)\end{array}$} & \multicolumn{2}{|c|}{$\begin{array}{l}\text { Wernicke's aphasics } \\
\qquad(N=4)\end{array}$} \\
\hline & RT & $d$ & RT & $d$ & RT & $d$ \\
\hline $\begin{array}{l}\text { First presentation } \\
\text { Second presentation }\end{array}$ & $\begin{array}{l}777 \\
713\end{array}$ & 64 & $\begin{array}{l}857 \\
792\end{array}$ & 6 & 967 & 67 \\
\hline Third presentation & 714 & 63 & 808 & 49 & 885 & 82 \\
\hline Fourth presentation & 709 & 68 & 804 & 53 & 880 & 87 \\
\hline
\end{tabular}

Note. Differences $(d)$ are measured relative to the first presentation. Significant main effects for Index of Presentation were obtained for the control subjects $(F(3,99)=48.62$, $\left.\mathrm{MS}_{\mathrm{z}}=1563, p<.0001\right)$, the Broca's aphasics $\left(F(3,18)=11.52, \mathrm{MS}_{\mathrm{e}}=2979, p<.001\right)$, and the Wernicke's aphasics $\left(F(3,9)=15.02, \mathrm{MS}_{e}=2462, p<.001\right)$. Significant differences in a post-hoc Newmans-Keuls test are marked by an asterisk. 
trolled processes are opaque to introspection and insensitive to manipulation through instruction. This enables them to be faster than the accessible ones. The inability of the vast majority of the subjects to report the presence of ambiguous words testifies to their unawareness of this aspect of the materials used in the experiments. It suggests that the suppression of the inappropriate reading of ambiguous words does not require awareness of their multiple meaning character, supporting the claim that ambiguity resolution is indeed a veiled process. The inhibition shown by the normal control subjects in Experiment 2 and 3 for the discordant noun-verb triplets supports the claim that the suppression of the inappropriate reading is a postlexical process. This process most likely refiects the integration of the first word prime with the biased meaning of the ambiguous word, resulting in inhibition for targets related to the unbiased meaning. Postlexical integration processes (i.e., semantic matching) already manifest themselves at short intervals between primes and targets (De Groot, 1984; Hodgson, 1991).

The normal control subjects showed the same pattern of results for all three ISIs. It is therefore difficult to separate at the level of the reported data priming effects due to automatic activation spreading from priming effects due to controlled processing. Thus it must be done in an indirect way. It has been argued (Neely, 1977, 1991; Posner \& Snyder, 1975) that the contribution of automatic spread of activation to priming effects increases with decreasing ISIs (or SOAs). Although the time range of ASA is only fairly well established for the visual domain, an ISI of 100 msec between auditorily presented words is short enough on any account of priming to pick up on the effects of automatic spread of activation. It is therefore very likely that ASA had its strongest contribution to the obtained priming effects in Experiment 2, most likely also contributed to the priming effects in Experiment 1, but had its weakest contribution in Experiment 3, if at all.

Figures 1 and 2 present the overall priming effects at the three ISIs for the normal control subjects and for the aphasic patients who participated in all experiments. As can be seen, the aphasic patients showed the normal priming pattern at the short ISIs. At the ISI of $1250 \mathrm{msec}$, the aphasic patients deviated from the normal control subjects in that significant priming effects were no longer obtained. This holds for both Broca's and Wernicke's aphasics equally. The patterns of results for the individual subjects are summarized in Appendix 2.

These results are strong evidence against the claim by Milberg et al. (1987) that Broca's aphasics are impaired in automatically accessing lexical-semantic information. ${ }^{7}$ Even at an ISI as short as $100 \mathrm{msec}$ the overall

\footnotetext{
${ }^{7}$ An anonymous reviewer suggested that the discrepancy between the results of the Broca's aphasics in the Milberg et al. study (1987) and the Broca's aphasics in this study might be due to qualitative differences in their functional deficits, rather than to a difference
} 


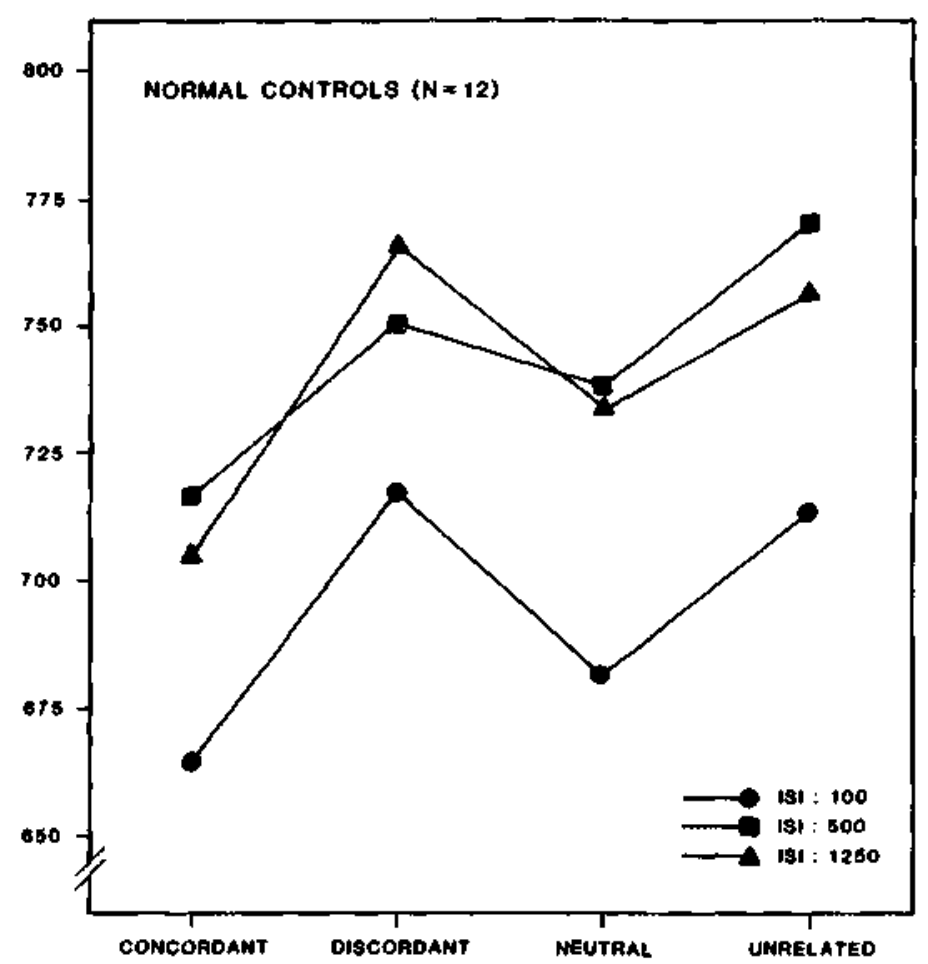

Fig. I. Means of the control subjects' median lexical decision latencies as a function of Priming Condition.

pattern of results for the Broca's aphasics did not differ from that of the normal control subjects. To date no other semantic priming study has used an interval short enough to allow firm conclusions with respect to the effects of automatic lexical-semantic processing in aphasic patients. The SOA of $2000 \mathrm{msec}$ in the study by Milberg and Blumstein (1981) using a visual presentation and the ISI of $500 \mathrm{msec}$ in studies using an auditory presentation (Blumstein et al., 1982; Chenery et al., 1990; Katz. 1988; Milberg et al.. 1987, 1988) are not short enough to guarantee that these studies mainly tapped the automatic spread of activation between related nodes in the semantic lexicon. Moreover, given the long latencies reported for the patients in these studies (between an estimated average of $1400 \mathrm{msec}$ for the Broca's aphasics and $2100 \mathrm{msec}$ for the Wernicke's

in the degree of severity. 1 cannot entirely discount this alternative explanation for the differences observed between both studies. However, I feel that an account in terms of a difference in degree of severity is preferable because the groups of Broca's aphasics in both studies do in fact show the same pattern of resuits, albeit at different ISIs (i.e., at the ISI of 500 msec in the Mitberg et al. study and at the ISI of 1250 msec in this study). 


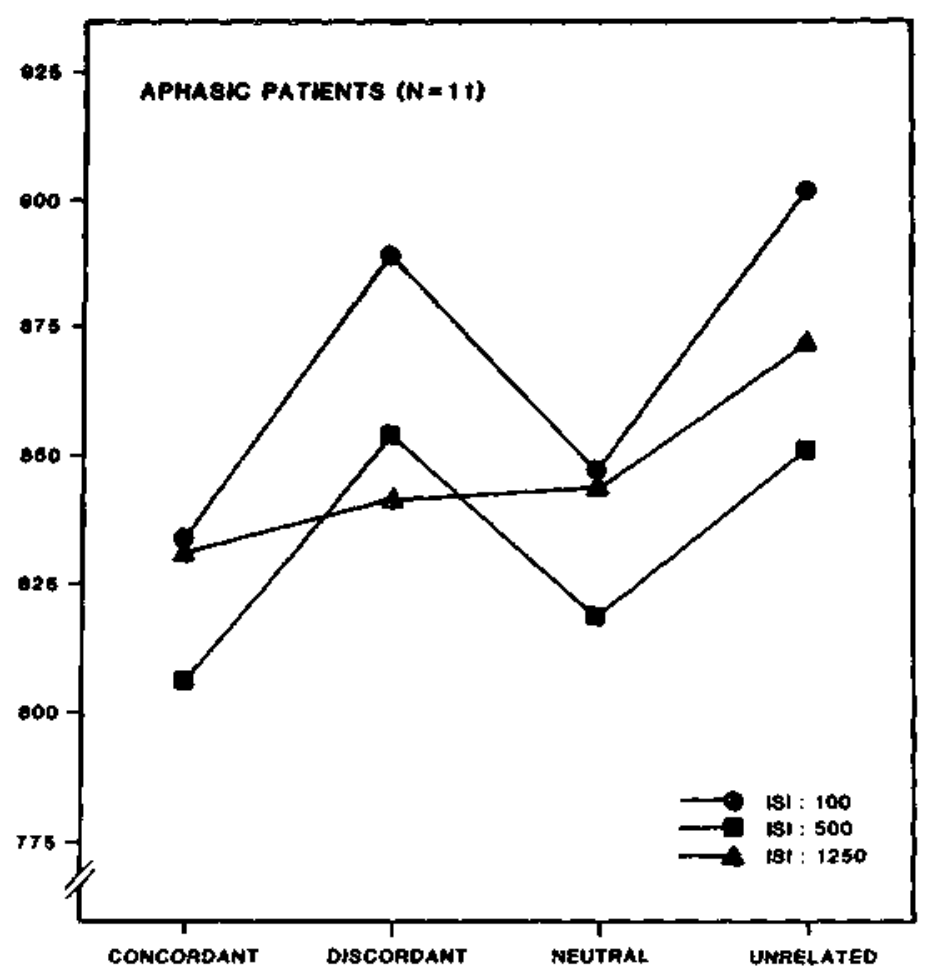

FIG. 2, Means of the aphasic patients median lexical decision latencies as a function of Priming Condition.

aphasics). postlexical strategic effects cannot be excluded. Conclusions with respect to possible impairments in automatic lexical-semantic processing in certain aphasic syndromes require the use of a range of SOAs (ISIs), including short ones that can be assumed to strongly tap automatic processing on the basis of well-established results in the priming literature (for an overview, see Neely, 1991). In addition, the experimental procedure should ensure that the measurement is as on-line as possible. That is, one has to be sure that the aphasic patients respond as quickly as possible given the general effects of their brain damage. The present research using both short and long ISIs indicates that neither Wernicke nor Broca patients have a specific deficit in automatic lexical-semantic processing.

With an increase in the ISl between the words, however, the aphasic patients started to show a pattern diverging from that of the normal control subjects. An ISI of $1250 \mathrm{msec}$ between the primes and the target no longer resulted in a reliable priming effect for both groups of aphasic patients. Priming effects thus have a tendency to be shorter lived in apha- 
sic patients than in normal control subjects. This reduction in the life span of semantic priming can be explained in different ways.

One possible explanation is that (the spread of activation decays more rapidly in the mental lexicon of the aphasic patients. As a consequence, the contribution of ASA to the overall priming effects covers a shorter time range than in the unimpaired language processor. Whereas in normal subjects residual priming due to ASA is still part of the overall priming effect at longer ISIs, in aphasic patients ASA might no longer contribute to priming effects at relatively long intervals. The faster decay can be caused by a higher decay rate of the activation collected by a semantic node in the lexicon or by a reduction in the initial levels of activation due to a general reduction in the signal-to-noise ratio for semantic nodes. Because the spread of activation to related nodes in the lexicon is a function of the activation collected by the source node, a reduction in its activation level will lead to a faster return to a resting state of activation. Consequently, a reduced temporal window for the automatic spread of activation will result.

Another explanation for the reduction of the priming effects with increasing ISIs focuses on the controlled processing of semantically related words. If controlled processes have their major contributions to priming effects at longer ISIs, the reduction in priming seen with longer ISIs might be caused by an impairment in controlled processing. The patients might have difficulties in generating and retaining a set of expected targets from the primes or in checking the semantic coherence of the words in the input string. In this case their comprehension deficits are beyond the level of automatic lexical access. The functional locus of these deficits might be postlexical, for instance in the integration of accessed lexical information into a higher order semantic representation of the whole utterance. With respect to the Wernicke's aphasics, this interpretation is corroborated by the relatedness judgement data. With respect to the Broca's aphasics, their increase in overall RTs at the shortest ISI indicates the possibility of a reduction in the computational resources required for these forms of controlled processing. Further support for an account in terms of impaired (or delayed) lexical integration processes is obtained in studies testing aphasic patients on the time course of the resolution of lexical ambiguity in sentence contexts (Hagoort, 1990).

For the Broca's aphasics, the overall priming effects were mainly due to the noun-noun ambiguities. Only the ISI of $500 \mathrm{msec}$ resulted in a significant priming effect for the noun-verb ambiguities. The absence of a stable priming effect for the noun-verb ambiguities even with a short ISI is not easy to explain. The morphological make-up of the noun-verb ambiguities used in this study might be involved in dampening the effects of priming.

In contrast to most English noun-verb ambiguities (e.g., watch) used 
in studies on the resolution of lexical ambiguity (Seidenberg et al., 1982; Tanenhaus et al., 1979), the majority of the Dutch noun-verb ambiguities in this study were morphologically complex, consisting of a stem and an inflectional suffix (e.g., wijk-en). In Dutch, the inflectional suffix -en is one of the plural markers for nouns. For verbs presented in isolation it indicates the infinitival form. All $\mathbf{1 6}$ noun-verb ambiguities in this study were in the infinitival verb form, while 12 referred to the plural reading of the noun and 4 to its nominative singular form.

It has been claimed that agrammatic patients have a specific deficit in the processing of free standing and bound closed class morphemes serving a syntactic function (e.g., Bradley, Garrett, \& Zurif, 1980; Friederici, 1983, 1988a,b; Tyler, Behrens, Cobb, \& Marslen-Wilson, 1990; Tyler \& Cobb, 1987). The proposed impairment in the access of syntactic information associated with inflectional suffixes might have hampered the identification of the grammatical form class of the morphologically complex word forms used in the present priming study. Although automatic semantic priming does not require the processing of the inflectional ending (cf. Tyler \& Marslen-Wilson, 1986; Zwitserlood, 1989), priming effects might have been partially masked by interference effects which possibly arose as a consequence of the impairment in rapidly using the suffixal information to determine the form class of the noun-verb ambiguities. In this respect it is worth mentioning that only one of the 16 unrelated baseline triplets contained a second prime with a morphologically complex word form. Priming effects in the other three triplet types were weak or absent relative to the morphologically simple, unrelated baseline.

Although the data do not allow a very detailed specification of the additional underlying impairment of the Broca's aphasics, it can be suggested that the selective decrease in the priming effects for the noun-verb ambiguities has something to do with an impairment in either the on-line morphological parsing of the complex word forms into a stem and an inflection or the on-line exploitation of the syntactic implications of the inflectional suffix. This might hamper access to the form-class information, which otherwise would have contributed to the selection of the contextually appropriate, and the suppression of the inappropriate reading of the ambiguity. ${ }^{8}$

\footnotetext{
${ }^{8}$ An additional explanation for the absence of a stable pattern of differential activation for concordant and discordant noun-verb triplets could be found in the morphological asymmetry between the verb and the noun readings. Although both are morphologically complex in the majority of cases, there is a clear difference in their markedness. The verb infinitive in Dutch is morphologically unmarked, while the plural form of the noun is clearly marked (Lapointe, 1985). In language production, agrammatic patients have a tendency to substitute the unmarked verb infinitive for verb forms marked for person and tense (Goodglass \& Geschwind, 1976; Lapointe, 1985). They might show an analogous preference in language comprehension to assign a word form its most unmarked interpretation. This
} 
The impairment that Wernicke patients show when explicitly asked to judge the semantic relations between words indicates that this type of task taps a different set of retrieval processes than the priming tasks do. The impairment of these patients in consciously elaborating on lexicalsemantic information, however, does not necessarily mean that the representational structure of their semantic memory is disturbed. The priming effects obtained for the Wernicke's aphasics in this and other studies (Blumstein et al., 1982; Milberg \& Blumstein, 1981; Milberg et al., 1987) suggests that the integrity of their semantic memory is largely preserved. Moreover, the normal repetition effects obtained for these patients indicate that they are able to form episodic traces, a prerequisite for the construction of a message representation from the speech input. However, their ability to consciously elaborate on linguistic material seems to be reduced. As in different forms of amnesia, one could characterize this specific deficit as "an impairment of consciousness" (Tulving, 1987; p. 75) rather than a disintegration of the underlying stored knowledge base.

would predict that independent of context, the Broca patients show a tendency to interpret the noun-verb ambiguities as referring to their verb readings. Whether this explanation bolds can easily be tested. Because half of the targets in the set of noun-verb triplets were related to the noun reading and half to the verb reading, a preference for the verb reading is indicated by an interaction between priming condition and the form class relatedness of the targets. A preference for the verb reading would induce facilitation for the verb-related targets relative to the unrelated baseline (e.g., stelen-dief vs. veiling-dief: "steal-thief" vs. "auction-thief"), but not for the noun-related targets (e.g. polsen-horloge vs, recepthorloge: "wrists-watch" vs. "recipe-watch"). An analysis of variance on the latency data of the noun-verb triplets for the three ISIs including the factor Form-Class Relatedness revealed that the interaction between Form-Class Relatedness and Priming Condition did not approach significance for the group of Broca's aphasics $\{F<1)$. The normal control subjects also failed to show a significant interaction between the two factors. This implies that the absence of differential priming effects for the concordant and discordant noun-verb triplets cannot be attributed to a preference to assign the noun-verb ambiguities their unmarked verb reading instead of their marked noun reading. The absence of a differential effect for verb-related targets and noun-related targets also excludes an explanation in terms of a citation form preference. In a recent syllable monitoring experiment in Dutch, some evidence has been found for a special status of citation forms during lexical access (Zwitserlood. Schriefers, Lahiri, \& van Donselaar. 1993). Given that in Dutch the verb infinitive is the citation form of verbs, while the noun plural is not the citation form of nouns, a citation form preference should likewise have led to an interaction between Form-Class Relatedness and Priming Condition. 


\section{APPENDIX 1}

Materials ireal word conditions)

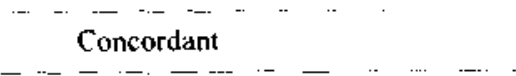
Discordant
Neutral

Noun-Noun Triplets

nieuws-artikel-winke overval-bank-sioel gedachte-inval-politie feest-kiel-hool sinaasappel-pers-krant kers1-piek-gulden oog-pupil-leerling deur-slot-einde

sinterkiaas-staf-medewerker loten-ton-regen bende-luig-paard pont-veer-vogel

huid-vel-papier

koning-vorst-kou jarig-slinger-klok poes-kater-drank

grijpen-pakken-kostuum

laken-kussen-vrijen

plant-varen-schip

stuiten-rolien-toneel

garage-wagen-durven

meten-peilen-boog

adel-graven-ga!

adel-graven-gat

gebit-kiezen-stemmen
landstreek-gebieden-bevel

verleiden-lokken-haren

heimwee-missen-kerk

vragen-polsen-horloge

vluchten-wijken-buurten

stro-balen-vervelen

pannen-stelen-dief

studie-leren-schoen

menen-artikel-winkel
orde-bank-stoel
schuit-inval-politie
gips-kiel-boot
eigenschap-pers-krant
dorp-piek-gulden
keuken-pupil-leerling
gezag-slot-einde
openjng-staf-medewerker
avond-ton-regen
forum-tuig-paard
respect-veer-vogel
lof-vel-papier
staart-vorst-kou
heer-slinger-klok
piano-kater-drank

Noun-Verb Triplets

termijn-pakken-kostuum

bezoek-kussen-vrijen

rest-varen-schip

inwoner-roljen-toneel

eczeem-wagen-durven

trachten-pijlen-boog

lood-graven-gat

jongen-kiezen-stemmen

fiets-gebieden-bevel

grieven-lokken-haren

maaltijd-missen-kerk

recept-polsen-horloge

gevoel-wijken-buurten

doof-balen-vervelen

veiling-stelen-dief

biel-leren-schoen
Unrelated

nieuws-menen-winkel overval-orde-sloel gedachte-schuj-polisie feest-gips-boot sinaasappe1-eigenschap-krant

kerst-dorp-gulden

oog-keuken-leerling

deur-gezag-einde

sinterklaas-opening-medewerke

loten-avond-regen

bende-forum-paard

pont-respect-vogel

huid-lof-papier

koning-staan-kou

jarig-heer-klok

poes-piano-drank

grijpen-termijn-kostuum

laken-bezoek-vrijen

plant-rest-schip

stuiten-inwoner-toneel

garage-eczeem-durven

meten-trachien-boog

adel-lood-gat

gebit-jongen-stemmen

landstreek-fiets-bevel

verleiden-grieven-haren

heimwee-maaltijd-kerk

vragen -recept-horloge

vluçhten-gevoel-buurten

stro-doof-verveten

pannen-veiling-dief

studie-biet-schoen

tiem-Jeren-schoen 


\section{APPENDIX 2}

Individual subject data for subjects participating in Experiments 1, 2, and 3. For each individual subject the rank ordering of the median RTs in the four priming conditions and the two ambiguity types is specified. In addition summary tables are presented which are based on these rank orders. Rank orders of individual patient data are only specified for the aphasic patients who participated in all four experiments. Abbreviations are as follows: concordant condition (c), discordant condition (d), neutral condition $(\mathrm{n})$, unrelated baseline condition $(\mathrm{u})$.

\section{Normal Control Subjects $(N=12)$, Noun-Noun Ambiguities}

\begin{tabular}{|c|c|c|c|}
\hline & $\mathrm{s} I=100 \mathrm{msec}$ & $I S I=500 \mathrm{msec}$ & ISI $=1250 \mathrm{mse}$ \\
\hline$(01)$ & $c<n<u<d$ & $\mathrm{c}<\mathrm{d}<\mathrm{n}<\mathrm{u}$ & $c<u<n<d$ \\
\hline (02) & $c<n<u<d$ & $d<c<n<u$ & $c<d<u<n$ \\
\hline (03) & $d<c<u<n$ & $n<d<u<c$ & $c<d<n<u$ \\
\hline (04) & $c<n<u<d$ & $c<d<n<u$ & $c<d<n<u$ \\
\hline (05) & $d<n<c<u$ & $c<n<d<w$ & $c<n<d<n$ \\
\hline (06) & $\mathbf{n}<\mathrm{c}<\mathrm{d}<\mathrm{u}$ & $c<d<n<u$ & $c<d<n<u$ \\
\hline (07) & $\mathbf{c}<\mathrm{d}=\mathbf{n}<\mathbf{u}$ & $\mathrm{c}=\mathrm{d}<\mathrm{u}<\mathrm{n}$ & $\mathrm{n}<\mathrm{u}<\mathrm{d}<\mathrm{c}$ \\
\hline (08) & $\mathbf{c}<\boldsymbol{n}<\boldsymbol{u}<\mathbf{d}$ & $\mathbf{d}<\mathbf{c}<\mathbf{n}<\mathbf{u}$ & $c<d<n<u$ \\
\hline (09) & $c<d<n<u$ & $c<n<d<u$ & $c<n<d<u$ \\
\hline (10) & $d<c<n<u$ & $d<n<c<u$ & $\mathbf{n}<\mathbf{d}<\mathrm{c}<\mathbf{u}$ \\
\hline (11) & $n<d<c<u$ & $d<c<n<n$ & $c<n<d<u$ \\
\hline (12) & $n<c<d<u$ & $\mathrm{n}<\mathrm{d}<\mathrm{c}<\mathrm{u}$ & $c<\mathrm{d}<\mathrm{u}<\mathrm{n}$ \\
\hline
\end{tabular}

Summary table of the rank ordering for RTs on triplets with noun-noun ambiguities. Mean ranking per Priming Condition.

\begin{tabular}{lccc} 
Priming Condition & ISI $=100$ & ISI $=\mathbf{5 0 0}$ & ISI $=1250$ \\
\cline { 1 - 2 } Concordant & 1.7 & 1.9 & 1.4 \\
Discordant & 2.6 & 1.8 & 2.5 \\
Neutral & 2.1 & 2.6 & 2.6 \\
Unrelated & 3.6 & 3.7 & 3.5 \\
& $\mathrm{c}<\mathrm{n}<\mathrm{d}<\mathrm{u}$ & $\mathrm{d}<\mathrm{c}<\mathrm{n}<\mathrm{u}$ & $\mathrm{c}<\mathrm{d}<\mathrm{n}<\mathrm{u}$
\end{tabular}

\section{Normal Control Subjects $(N=12$ ), Noun-Verb Ambiguities}

\begin{tabular}{|c|c|c|c|}
\hline & $I=100 \mathrm{msec}$ & ISI $=500 \mathrm{msec}$ & ISI $=1250 \mathrm{msec}$ \\
\hline (0I) & $c<n<u<d$ & $c<n<d<u$ & $n<c<u<d$ \\
\hline (02) & $c<u<n<d$ & $c<n<u<d$ & $c<\mathbf{u}<\mathbf{n}<\mathrm{d}$ \\
\hline (03) & $n<c<u<d$ & $c<d<u<n$ & $c<n<u<d$ \\
\hline (04) & $c<n<d<u$ & $\mathrm{n}<\mathrm{c}<\mathrm{u}<\mathrm{d}$ & $c<n<u<d$ \\
\hline (0S) & $c<u<n<d$ & $c<n<u<d$ & $\mathrm{n}<\mathrm{c}<\mathrm{u}<\mathrm{d}$ \\
\hline
\end{tabular}


Normal Control Subjects-Continued

\begin{tabular}{|c|c|c|c|}
\hline & $1=100 \mathrm{msec}$ & ISI $=500 \mathrm{msec}$ & $1 \mathrm{SI}=1250 \mathrm{msec}$ \\
\hline (06) & $c<n<u<d$ & $\mathbf{c}<\mathbf{n}<\mathbf{u}<\mathbf{d}$ & $n<c<u<d$ \\
\hline (07) & $\mathbf{c}<\mathbf{u}<\mathbf{d}<\mathbf{n}$ & $c<d<0<n$ & $\mathbf{c}<\mathbf{n}<\boldsymbol{d}<\mathbf{u}$ \\
\hline (08) & $\mathrm{n}<\mathrm{c}<\mathrm{u}<\mathrm{d}$ & $\mathrm{n}<\mathrm{c}<\mathrm{u}<\mathrm{d}$ & $\mathbf{n}<\mathbf{u}<\mathrm{c}<\mathrm{d}$ \\
\hline (09) & $\mathbf{n}<\mathbf{u}<\boldsymbol{c}<\mathrm{d}$ & $c<n<u<d$ & $c<n<u<d$ \\
\hline (10) & $c<n<u<d$ & $\mathbf{n}<\boldsymbol{c}<\boldsymbol{u}<\mathbf{d}$ & $c<u<n<d$ \\
\hline (11) & $c<n<u<d$ & d $<\mathrm{c}<\mathrm{n}<\mathrm{u}$ & $\mathbf{c}<\mathbf{n}<\mathbf{u}<\mathbf{d}$ \\
\hline (12) & $\mathrm{n}<\mathrm{c}<\mathrm{u}<\mathrm{d}$ & $\mathrm{n}<\mathrm{c}<\mathrm{d}<\mathrm{u}$ & $u<n<c<d$ \\
\hline
\end{tabular}

Summary table of the rank ordering for RTs on triplets with noun-verb ambiguities. Mean ranking per Priming Condition.

\begin{tabular}{|c|c|c|c|}
\hline Priming Condition & {$[S]=100$} & $I S I=500$ & ISI $=1250$ \\
\hline Concordant & 1.4 & 1.4 & 1.6 \\
\hline Discordant & 3.8 & 3.3 & 3.9 \\
\hline Neutral & 2.0 & 2.1 & 1.8 \\
\hline Unrelated & 2.8 & 3.3 & 2.7 \\
\hline
\end{tabular}

Aphasic Patients $(N=11)$, Noun-Noun Ambiguities

\begin{tabular}{|c|c|c|}
\hline ISI $=100 \mathrm{msec}$ & ISI $=500 \mathrm{msec}$ & $I S I=1250 \mathrm{msec}$ \\
\hline$c<n<d<u$ & $\mathrm{n}<\mathrm{d}<\mathrm{c}<\mathrm{u}$ & $\mathbf{c}<\mathbf{d}<\mathbf{n}<\mathbf{u}$ \\
\hline $\mathbf{c}<\mathbf{n}<\mathbf{d}<\mathbf{u}$ & $\mathbf{d}<\mathbf{c}<\mathbf{n}<\mathbf{u}$ & $c<d<u<n$ \\
\hline$c<d<n<u$ & $\mathbf{d}<\mathrm{u}<\boldsymbol{n}<\mathrm{c}$ & $n<d<c<u$ \\
\hline $\mathbf{n}<\mathbf{c}<\mathbf{d}<\mathbf{u}$ & $c<\mathbf{u}<\mathbf{d}<\mathbf{n}$ & $\mathrm{n}<\mathrm{d}<\mathrm{c}<\boldsymbol{u}$ \\
\hline$c<n<d<u$ & $\mathrm{n}<\boldsymbol{c}<\boldsymbol{d}<\mathrm{u}$ & $c<d<n<u$ \\
\hline$n<c<d<u$ & $n<c<u<d$ & $d<\pi<c<u$ \\
\hline$c<n<u<d$ & $n<d<c<u$ & $d<n<u<c$ \\
\hline$n<c<d<u$ & $c<n<u<d$ & $c<d<u<n$ \\
\hline$c<\mathbf{d}<\boldsymbol{u}<\mathbf{n}$ & $\mathrm{n}=\mathrm{d}<\boldsymbol{u}<\mathrm{c}$ & $n<d<<u<c$ \\
\hline $\boldsymbol{c}<\boldsymbol{d}<\boldsymbol{n}<\mathbf{u}$ & $\mathbf{u}<\mathrm{n}<\mathrm{c}<\mathrm{d}$ & $c<u<d<n$ \\
\hline $\mathbf{c}<\mathrm{d}<\boldsymbol{n}<\mathbf{u}$ & $c<d<n<u$ & $d<u<c<n$ \\
\hline
\end{tabular}

Summary table of the rank ordering for RTs on triplets with noun-noun ambiguities. Mean ranking per Priming Condition.

$\begin{array}{lccc}\text { Priming Condition } & \text { IS1 }=100 & \text { ISI }=500 & \text { ISI }=\mathbf{I 2 5 0} \\ \text { Concordant } & 1.3 & \ldots \ldots \ldots \ldots & 2.3 \\ \text { Discordant } & 2.7 & 2.4 & 1.8 \\ \text { Neutral } & 2.2 & 2.5 & 2.6 \\ \text { Unrelated } & 3.8 & 3.0 & 3.3 \\ & c<n<d<u & n<c<d<u & d<c<n<u\end{array}$




\section{Aphasic Patients $(N=11)$, Noun-Verb Ambiguities}

$$
\text { ISI }=100 \mathrm{msec}
$$

(01)

(02)

(03)

(04)

(05)

(06)

(07)

(08)

(09)

(10)

(t1)

$$
\begin{aligned}
& n<u<d<c \\
& c<d<u<n \\
& n<c<u<d \\
& c<d<u<n \\
& d<c<u<n \\
& n<u<c<d \\
& n<c<u<d \\
& n<c<d<u \\
& n<c<u<d \\
& u<c<n<d \\
& c<n<d<u
\end{aligned}
$$
$I S I=1250 \mathrm{msec}$
$c<n<u<d$ $c<u<n<d$

\begin{tabular}{|c|c|c|c|}
\hline Priming Condition & $I S I=100$ & $I S I=500$ & $I S I=I 250$ \\
\hline Concordant & 2.0 & 1.8 & 2.1 \\
\hline Discordant & 3.1 & 3.4 & 3.2 \\
\hline Neutral & 2.1 & 2.1 & 1.8 \\
\hline \multirow[t]{2}{*}{ Unrelated } & 2.8 & 2.7 & 2.9 \\
\hline & $c<n<u<d$ & $c<n<\boldsymbol{u}<d$ & $\mathrm{n}<\mathrm{c}<\mathrm{u}<\mathrm{d}$ \\
\hline
\end{tabular} $\mathbf{u}<\mathbf{n}<\mathrm{c}<\mathbf{d}$ $c<n<d<u$ $c<d<u<n$ $\mathrm{n}<\mathrm{u}<\mathrm{c}<\mathrm{d}$ $\mathrm{d}<\mathrm{n}<\mathrm{u}<\mathrm{c}$ $n<u<c<d$ $\mathrm{n}<\mathrm{c}<\mathrm{d}<\mathrm{u}$ $n<c<d<u$ $n<c<d<u$

Summary table of the rank ordering for RTs on triplets with noun-verb ambiguities. Mean ranking per Priming Condition.

\section{REFERENCES}

Balota, D. A., \& Chumbley, J. 1. 1984. Are lexical decisions a good measure of lexical access? The role of word freguency in the neglected decision stage. Journal of Experimental Psychology: Human Perception and Performance, 10, 340-357.

Balota, D. A., \& Duchek. J. M. 1991. Semantic priming effects, lexical repetition effects, and contextual disambiguation effects in healthy aged individuals and individuals with senile dementia of the Alzheimer type. Brain and Langtwage, 40, 181-201.

Blumstein. S. E. 1982. Classification in aphasia. Paper presented at the Annual Meeting of the Academy of Aphasia, Lake Mohonk, NY.

Blumstein, S. E., Milberg, W., \& Shrier, R. 1982. Semantic processing in aphasia: Evidence from an auditory texical decision task. Brain and Language, 17, 30I-315.

Bradley, D. C.. Garrett, M. F., \& Zurif. E. B. 1980. Syntactic deficits in Broca's aphasia. In D. Caplan (Ed.). Biological studies of mental processes. Cambridge, MA: MIT Press.

Chenery, H. J., Ingram, J. C. L., \& Murdoch, B. E. 1990. Automatic and volitional semantic processing in aphasia. Brain and Language, 38, 215-232.

Collins, A. M., \& Loftus, E. F. 1975. A spreading-aclivation theory of semantic processing. Psychological Review, 82, 407-428.

Conrad, C. 1974. Context effects in sentence comprehension: A study of the subjective lexicon. Memory \& Cognision, 2, 130-138.

Cottretl, G. W. 1988. A model of lexical access of ambiguous words. In S. L. Small, G. W. Cottrell, \& M. K. Tanenhaus (Eds.), Lexical ambiguity resolution: Perspectives 
from psycholinguistics, neuropsychology and artificial intelligence. San Mateo, CA: Kaufmann.

Cottrell, G. W.. \& Small, S. L. 1983. A connectionist scheme for modelling word sense disambiguation. Cognirion and Brain Theory, 6, 89-120.

De Bleser, R.. Wilmes, K., Graetz, P., \& Hagoort. P. 1991. De Akense afasie test: Psychometrische kenmerken van de Nederlandstalige versie. Logopedie en Foniasrie, 63. 207-217.

De Grool, A. M. B. 1984. Primed lexical decision: Combined effects of the proportion of related prime-target pairs and the stimulus-onset asynchrony of prime and target. The Quarterly Journal of Experimental Psychology, 36A, 253-280.

De Groot. A. M. B. 1990. The locus of the associative-priming effect in the mental lexicon: Evidence from lexical and semantic classification studies. In D. A. Balota, G. B. Flores d'Arcais. \& K. Rayner (Eds.). Comprehension processes in reading. Hillsdale, NJ: Erlbaum.

De Groot, A. M. B., Thomassen, A. J. W. M., \& Hudson, P. T. W. 1982. Associative facilitation of word recognition as measured from a neutral prime. Memony \& Cognition, 10, 358-370.

De Groot. A. M. B., Thomassen. A. J. W. M.. \& Hudson, P. T. W. 1986. Primed lexical decision: The effect of varying the stimulus-onset asynchrony of prime and target. Acta Psychologica, 61, 17-36.

Den Heyer, K., Goring, A., \& Dannenbring, G. L. 1985. Semantic priming and word repetition: The two effects are additive. Journal of Memory and Language, 24, $699-716$.

Evelt, L. J., \& Humphreys, G. W. 1981. The use of abstract graphemic information in lexical access. Quarterly Journal of Experimental Psychology, 33A, 325-350.

Feustel, T. C.. Shiffrin. R. M.. \& Salasoo, A. 1983. Episodic and lexical contributions to the repetition effect in word identification. Journal of Experimensal Psychology: General, 112, 309-346.

Frauenfelder, U. H., \& Tyler, L. K. 1987. The process of spoken word recognition: An introduction. Cognition, 25, 1-20.

Friederici, A. D. 1983. Aphasics' perception of words in sentential context: Some real-time processing evidence. Neuropsychologia. 21, 35I-358.

Friederici, A. D. 1988a. Autonomy and automaticity: Accessing function words during sentence comprehension. In G. Denes, C. Semenza, \& P. Bisiacchi (Eds.). Perspectives on cognitive neuropsychology. Hove, UK: Erlbaum.

Friederici, A. D. 1988b. Agrammatic comprehension: Picture of a computational mismatch. Aphasiology, 2, 279-284.

Friederici, A. D., \& Kilborn, K. 1989. Temporal constraints on language processing: Syntactic priming in Broca's aphasia. Journat of Cognitive Neuroscience, 1, 262-272.

Friedman, R. B.. Glosser, G., \& Diamond. H. 1988. Semantic versus associative lexical priming in Alzheimer's disease and fluent aphasia. Paper presented at the Annual Meeting of the Academy of Aphasia, Montreal, Canada.

Goodglass. H., \& Baker, E. 1976. Semantic field, naming, and auditory comprehension in aphasia. Brain and Language. 3, 359-374.

Goodglass, H., \& Geschwind. N. 1976. Language disorders (aphasia). In E. Carterette \& M. Friedman (Eds.), Handbook of perception: Vol. VH. Language and speech. New York: Academic Press.

Graetz, P., de Bleser, R., Willmes, K., \& Heeschen, C. 1991. De Akense afasie test: Constructie van de Nederlandstalige versie, Logopedie en Foniatrie, 63, 58-68.

Graf, P., \& Mandler, G. 1984. Activation makes words more accessible, but not necessarily more retrievable. Journal of Verbat Learning and Verbal Behavior, 23, 553-568.

Green, D. M.. \& Swets, J. A. 1966. Signal detection theory and psychophysics. New York: Wiley. 
Gier, J. B. 197I. Nonparametric indexes for sensitivity and bias: Computing formulas. Psychological Bulletin, 75, 424-429.

Hagoort, P. 1989. Processing of lexical ambiguities: A comment on Milberg, Blumstein. and Dworetzky 1987. Brain and Language, 36, 335-348.

Hagoort, P. 1990. Tracking the time course of language understanding in aphasia. Published doctoral dissertation, Nijmegen University.

Hodgson. J. M. 1991. Informational constraints on pre-lexical priming. Language and Cognirive Processes, 6, 169-205.

Holley-Wilcox, P., Blank, M. A. 1980. Evidence for multiple access in the processing of isolated words. Journal of Experimental Psychology: Human Perception and Performance, 6, 75-84.

Humphreys, G. W. 1985. Attention, automaticity, and autonomy in visual word processing. In D. Besner, T. G. Waller, \& E. M. Mackinnon (Eds.), Reading research: Advances in theory and practice. Toronto: Academic Press.

Katz, W. F. 1988. An investigation of lexical ambiguity in Broca's aphasics using an auditory lexical priming technique. Neuropsychologia, 26, 747-752.

Keefe, D. E., \& Neely, J. H. 1990 . Semantic priming in the pronunciation task: The role of prospective prime-generated expectancies. Memory \& Cognition, 18, 289-298.

Lapointe, S. G. 1985. A theory of verb form use in the speech of agrammatic patients. Brain and Language, 24, 100-IS5.

Leveit, W. J. M. 1989. Speaking: From intention to articulation. Cambridge, MA: MIT Press.

Linebarger, M. C., Schwartz, M. F., \& Saffran, E. M. 1983. Sensitivity to grammatical structure in so-called agrammatic aphasics. Cognition, 13, 361-392.

Marcel, A. 3. 1980. Conscious and preconscious recognition of polysemous words: Locating the selective effects of prior verbal context. In R. S. Nickerson (Ed.), Atrention and performance VIII. Hillsdale. NJ: Erlbaum.

Marslen-Wilson, W. D. 1984. Function and process in spoken word-recognition. In H. Bouma \& D. G. Bouwhuis (Eds.), Aftention and Performance $X$ : Control of language processes. Hillsdale, NJ: Erlbaum.

Marslen-Wilson, W. D. 1987. Functional parallelism in spoken word-recognition. Cognition, 25, 71-102.

McClelland, J. L., \& Rumelhart, D. E. 198I. An interactive activation model of context effects in letter perception: Part 1. An account of basic findings. Psychological Review, 88, 375-407.

Meyer, D. E., \& Schvaneveldt, R. W. 1971. Facilitation in recognizing pairs of words: Evidence of a dependence between retrieval operations. Journal of Experimental Psy* chology, 90, 227-234.

Milberg, W., \& Blumstein, S. E. 1981. Lexical decision and aphasia; Evidence for semantic processing. Brain and Language, 14, 371-385.

Milberg, W., Blumstein, S. E., \& Dworetzky, B. 1987. Processing of lexical ambiguities in aphasia. Brain and Language, 31, 138-150.

Milberg, W., Blumstein, S. E.. \& Dworetzky, B. 1988. Phonological processing and lexical access in aphasia. Brain and Language, 34, 279-293.

Neely, J. H. 1977. Semantic priming and retrieval from lexical memory: Roles of inhibitionless spreading activation and limited-capacity attention. Journal of Experimental Psychology: General. 106, 226-254.

Neely, J. H. 1991. Semantic priming effects in visual word recognition: A selective review of current findings and theories. In D. Besner \& $G$. Humphreys (Eds.), Basic processes in reading: Visual word recognition. Hillsdale, NJ: Erlbaum.

Neely, J. H., \& Keefe, D. E. 1989. Semantic context effects on visual word processing: A hybrid prospective/retrospective processing theory. In G. H. Bower (Ed.), The psy- 
chology of learning and motivation: Advances in research and theory. New York: Academic Press. Vol. 24.

Neely, J. H., Keefe, D. E., \& Ross, K. L. 1989. Semantic priming in the lexical decision task: Roles of prospective prime-generated expectancies and retrospective semantic matching. Journal of Experimental Psychology: Learning, Memory, and Cognition, 15, $1003-1019$.

Oden. G. C., \& Spira, J. L. 1983. Influence of context on the activation and selection of ambiguous word senses. Quarrerly Journal of Experimental Psychology, 35A, 51-64.

Posner, M. I., \& Snyder, C. R. R. 1975. Attention and cognitive control. In R. L. Solso (Ed.), Information processing and cognition: The Loyola symposium. Hillsdale, NJ: Erlbaum.

Prather, P. A.. \& Swinney, D. A. 1988. Lexical processing and ambiguity resolution: An autonomous process in an interactive box. In S. L. Small, G. W. Cottrell, \& M. K. Tanenhaus (Eds.), Lexical ambiguity resolution: Perspectives from psycholinguistics. neuropsychology and artificial intelligence. San Mateo, CA: Kaufmann.

Renault, B., Signoret, J.-L., Debruille, B., Breton, F., \& Bolgert, F. 1989. Brain potentials reveal covert facial recognition in prosopagnosia. Neuropsychologia, 29, 905-912.

Schacter, D. L. 1987. Implicit memory: History and current status. Journol of Experimentat Psychology: Learning, Memory, and Cognition, 13, 501-518.

Schvaneveldı, R. W., Meyer, D. E., \& Becker, C. A. 1976. Lexical ambiguity, semantic context, and visual word recognition. Journal of Experimental Psychology: Human Perception and Performance. 2, 243-256.

Seidenberg, M. S. . Tanenhaus. M. K. Leiman, J, M.. \& Bienkowski, M. 1982. Automatic access of the meanings of ambiguous words in context: Some limitations of knowledge based processing. Cognitive Psychology, 14, 489-537.

Seidenberg. M. S., Waters, G. S., Sanders, M., \& Langer, P. 1984. PTe- and postlexicai loci of contextual effects on word recognition. Memory \& Cognition. 12, 315-328.

Shallice, T., \& Saffran, E. 1986. Lexical processing in the absence of explicil word identification: Evidence from a letter-by-letter reader. Cognitive Neuropsychology, 3, 429-458.

Shiffrin, R. M., \& Schneider, W, 1977. Controlled and automatic human information processing: Il. Perceptual learning, automatic attending, and a general theory. Psychological Review, 84, 127-190.

Simpson, G. B. 1984. Lexical ambiguity and its role in models of word recognition. Psychological Bulletin. 96, 316-340.

Squire, L. R., \& Cohen. N. J. 1984. Human memory and amnesia. In J. McGaugh, G. Lynch, \& N. Weinberger (Eds.), Proceedings of the conference on the neurobiology of learning and memory. New York: Guilford Press.

Tanenhaus, M. K., Leiman, J. M., \& Seidenberg. M. S. 1979. Evidence for multiple stages in the processing of ambiguous words in syntactic contexts. Journal of Verbal Learning and Verbal Behavior, 18, 427-440.

Tulving, E. 1984. Precis of Elements of episodic memory. The Behavioral and Brain Sciences, 7, 223-268.

Tulving. E. 1987. Multiple memory systems and consciousness. Human Neurobiology, 6, 67-80.

Tulving. E. \& Schacter, D. L. 1990. Priming and human memory systems. Science, 247, $301-306$.

Tyler, L. K.. Behrens, S., Cobb, H., \& Marslent-Wilson, W. 1990. Processing distinctions between stems and affixes: Evidence from a non-fluent aphasic patient. Cognition, 36, 129-153.

Tyler, L. K., \& Cobb, H. 1987. Processing bound grammatical morphemes in context: The case of an aphasic patient. Language and Cognitive Processes, 2, 245-262. 
Tyler, L. K., \& Marslen-Wilson, W. D. 1986. The effects of context on the recognition of polymorphemic words. Journat of Memory and Language. 25, 741-752.

Verfaellie, M. . Cermak. L. S., Blackford, S. P., \& Weiss, S. 1990. Strategic and automatic priming of semantic memory in alcoholic Korsakoff patients. Brain and Cognition. 13, 178-192.

Volpe, B. T., LeDoux, J. E., \& Gazzaniga, M. S. 1979. Information processing of visual stimuli in an 'extinguished' field. Nature, 282, 722-724.

Weiskrant2. L. 1986. Blindsight: A case study and implications. Oxford: Clarendon Press.

Whitehouse, P., Caramazza, A., \& Zurif, E. 1978. Naming in aphasia: Interactivity effects of form and function. Brain and Language, 6, 63-74.

Winer, B. J. 1971. Statistical principles in experimental design. New York: McGraw-Hill.

Zurif. E. B., Caramazza, A. Myerson, R.. \& Galvin, J. 1974. Semantic feature representations for normal and aphasic language. Brain and Language, 1, 167-187.

Zwitserlood. P. 1989. The locus of the effects of sentential-semantic context in spoken-word processing. Cognition, 32, 25-64.

Zwitserlood, P., Schriefers, H., Lahiri, A., \& van Donselaar, W. 1993. The role of the syliable in the perception of Dutch. Journal of Experimental Psychology: Learning. Memory, and Cognition. 19, $1-12$. 